\title{
WestVirginiaUniversity
}

THE RESEARCH REPOSITORY @ WVU

Graduate Theses, Dissertations, and Problem Reports

2000

\section{Sonovoltammetric detection of cadmium (II) at mercury thin film electrodes}

Stacey L. Clark

West Virginia University

Follow this and additional works at: https://researchrepository.wvu.edu/etd

\section{Recommended Citation}

Clark, Stacey L., "Sonovoltammetric detection of cadmium (II) at mercury thin film electrodes" (2000). Graduate Theses, Dissertations, and Problem Reports. 1079.

https://researchrepository.wvu.edu/etd/1079

This Thesis is protected by copyright and/or related rights. It has been brought to you by the The Research Repository @ WVU with permission from the rights-holder(s). You are free to use this Thesis in any way that is permitted by the copyright and related rights legislation that applies to your use. For other uses you must obtain permission from the rights-holder(s) directly, unless additional rights are indicated by a Creative Commons license in the record and/ or on the work itself. This Thesis has been accepted for inclusion in WVU Graduate Theses, Dissertations, and Problem Reports collection by an authorized administrator of The Research Repository @ WVU. For more information, please contact researchrepository@mail.wvu.edu. 
SONOVOLTAMMETRIC DETECTION OF CADMIUM (II)

AT MERCURY THIN FILM ELECTRODES

\author{
Stacey L. Clark
}

Thesis

Submitted to the College of Arts and Sciences

Of

West Virginia University

In Partial Fulfillment of the Requirements for

The Degree of Master of Science

Ronald B. Smart, Ph.D., Chair

Paul W. Jagodzinski, Ph.D.

Fred L. King, Ph.D.

Department of Chemistry

Morgantown, WV

2000 


\author{
ABSTRACT \\ Sonovoltammetric Detection of Cadmium (II) at Mercury Thin Film Electrodes \\ Stacey L. Clark
}

The application of ultrasound has been used previously in many areas of chemistry. The use of ultrasound to enhance the mass transport of cadmium (II) to a mercury film electrode (MFE) was investigated using square wave stripping voltammety. Both platinum and glassy carbon electrodes were examined as support materials for the mercury film and the results were compared to a dialysis membrane-covered glassy carbon MFE. The platinum electrode behaved in an unusual manner and appeared to be greatly affected by the ultrasound. The glassy carbon MFE also exhibited loss of sensitivity after exposure to ultrasound; however, when the glassy carbon surface was roughened prior to mercury plating, results were more promising. 


\section{ACKNOWLEDGEMENTS}

I would like to express my gratitude to Dr. Ronald B. Smart for providing me the opportunity for this research project. I would like to thank him for his guidance and encouragement, but most of all for his patience and sense of humor. I would like to thank Dr. Fred L. King and Dr. Paul W. Jagodzinski for their careful review of this manuscript and for the time they sacrificed in serving on my research committee.

Special thanks are extended to Carol Babyak for her help and support. I would also like to acknowledge the graduates in the analytical section for all the help and expertise they extended during the writing of this manuscript.

Finally, I extend my deepest appreciation to my parents, Jack and Lorene Clark, for all of their help and support; as well as for the fathomless faith they seem to have in me. 


\section{TABLE OF CONTENTS}

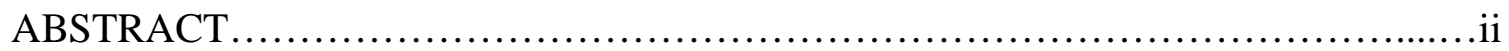

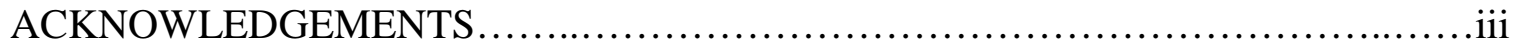

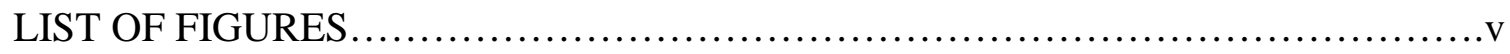

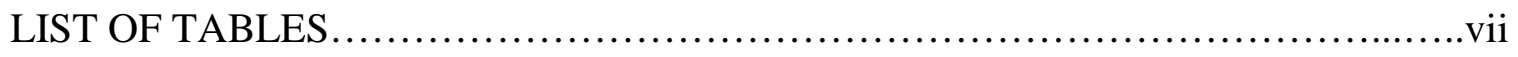

CHAPTER I: INTRODUCTION...................................................

Anodic Stripping Voltammetry ...........................................

Differential Pulse and Square Wave Voltammetry................................ 3

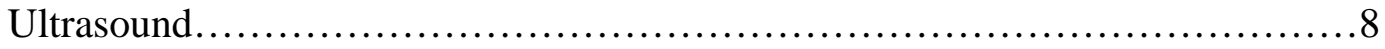

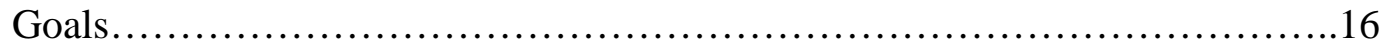

CHAPTER II: THE PLATINUM ELECTRODE.....................................17

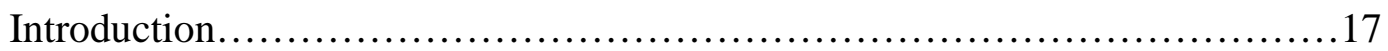

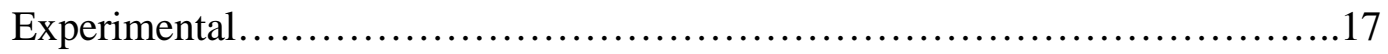

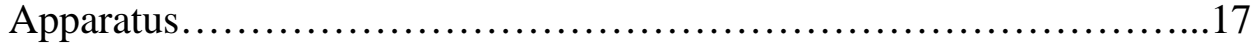

Reagents and Solutions............................................

Dialysis Membrane ..............................................20

Mercury Plating and Electrode Preconditioning.......................20

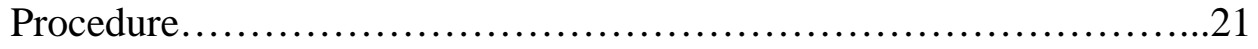

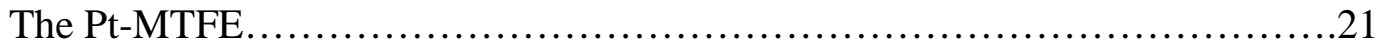

Effect of Ultrasound on Current.......................................25

Effect of Ultrasound on MTF Plating...............................25

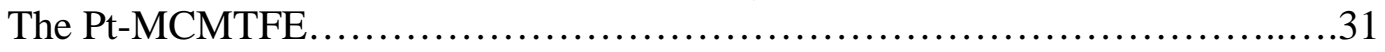

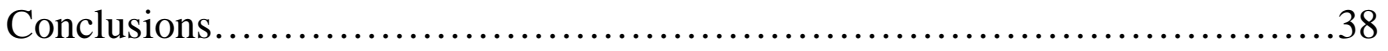

CHAPTER III: THE GLASSY CARBON ELECTRODE ..............................41

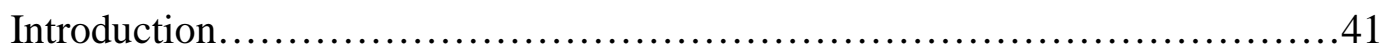

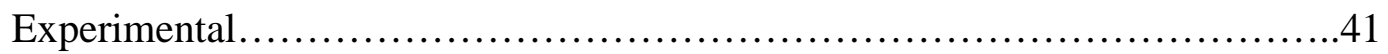

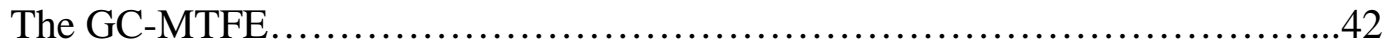

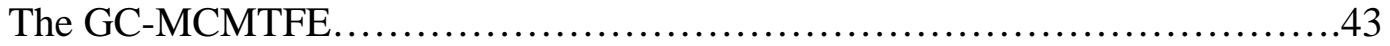

Effect of Ultrasound on Current......................................43

Effect of Ultrasound on the Diffusion Coefficient of $\mathrm{Cd}^{2+} \ldots \ldots \ldots \ldots \ldots . . . .51$

Effect of Ultrasound on Stripping Potential..............................52

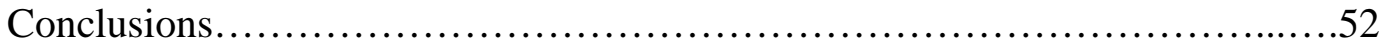

CHAPTER IV: FUTURE WORK.................................................54

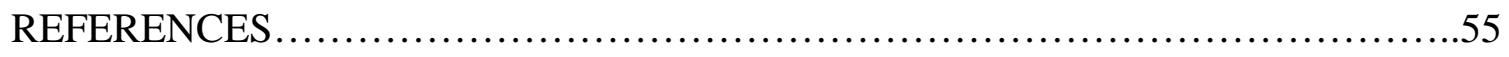




\section{LIST OF FIGURES}

Figure No.

Page No.

Figure 1. Differential Pulse Voltammetry........................................ 4

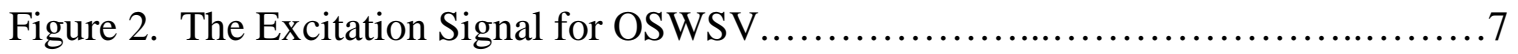

Figure 3. The Electrochemical Cell............................................18

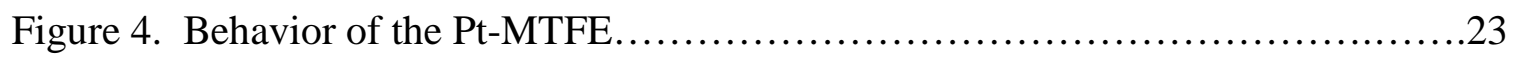

Figure 5. The Effect of Multiple Injections on the Pt-MTFE.........................24

Figure 6. The Effect of Ultrasound on Current......................................26

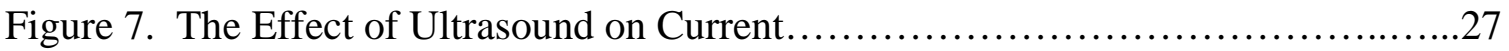

Figure 8. The Effect of Ultrasound on Current......................................28

Figure 9. The Effect of Ultrasound Distance on Plating a MTF Onto Pt...............29

Figure 10. The Effect of Ultrasound Distance on Plating a MTF Onto Pt................30

Figure 11. Comparison of MTF Plated While Stirring to One Plated With Ultrasound..32

Figure 12. Comparison of MTF Plated While Stirring to One Plated With Ultrasound..33

Figure 13. Comparison of MTF Plated While Stirring to One Plated With Ultrasound..34

Figure 14. Maximum Current vs. Ultrasound Distance During Cd Analysis...............35

Figure 15. Comparison of MTF Plating Times.........................................

Figure 16. Comparison of MTF Plating Times.........................................

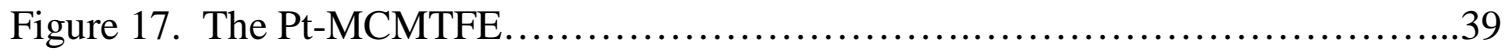

Figure 18. Behavior of the GC-MCMTFE ........................................ 44

Figure 19. The Effect of Ultrasound on Current....................................45

Figure 20. The Effect of Pitting on the GC-MCMTFE...............................47 
Figure 21 The Pitted GC-MCMTFE.......................................48

Figure 22. The GC-MCMTFE With a 15 Second Quiet Deposition.....................50 


\section{LIST OF TABLES}

Table No.

Page No.

Table 1. Common Parameters of DPASV .....................................6

Table 2. Common Parameters of OSWSV ....................................

Table 3. Experimental Parameters Used for OSWSV ..............................22 


\section{CHAPTER I \\ INTRODUCTION}

\section{Anodic Stripping Voltammetry}

Current is measured as a function of the applied cell voltage in voltammetry. Anodic stripping voltammetry (ASV) of metal ions consists of a deposition (reduction) step followed by a stripping (oxidation) step. During the deposition, a metal ion analyte is reduced by applying a potential more negative than the half-wave potential of the ion. This process is described by the following equation:

$$
\mathrm{M}^{\mathrm{n}+}+\mathrm{ne}^{-} \rightarrow \mathrm{M}
$$

where $\mathrm{M}^{\mathrm{n}+}$ is any metal ion. After the metal ion has been deposited onto the electrode surface, the voltage is scanned in a positive direction. When the applied voltage reaches the formal potential of the metal ion/metal $\left(\mathrm{E}^{0}\right)$, the deposited metal is oxidized:

$$
\mathrm{M} \rightarrow \mathrm{M}^{\mathrm{n}+}+\mathrm{ne}^{-}
$$

The anodic current measured during this oxidation step is linear with $\left[\mathrm{M}^{\mathrm{n}+}\right]$.

During the deposition step, the metal ions diffuse from the bulk solution toward the electrode and a depletion layer $(\delta)$ forms at the surface of the electrode. The limiting current is given by the following equation:

$$
I_{\lim }=\frac{n F A D_{M}\left[M^{n+}\right]}{\delta}
$$


where $\mathrm{n}$ is the number of electrons transferred, $\mathrm{F}$ is Faraday's constant, $\mathrm{A}$ is the area of the electrode, $\mathrm{D}$ is the diffusion coefficient of $\mathrm{M}^{\mathrm{n}+}$, and $\delta$ is the thickness of the depletion layer. One way to increase the sensitivity of ASV is to decrease $\delta$, and methods are available to increase the mass transport of the system. Stirring the solution for stationary electrodes and the use of a rotating disc electrode (RDE) are examples of methods used to increase mass transport (decrease $\delta$ ) during the deposition step.

Another way to increase the sensitivity of ASV is to increase the concentration of metal in the deposit. The hanging mercury drop electrode (HMDE), the working electrode is a mercury drop which is viable for any species which is soluble in liquid mercury. The mercury drop is placed in a cell which contains $\mathrm{M}^{\mathrm{n}+}$, and as $\mathrm{M}^{\mathrm{n}+}$ is reduced to $\mathrm{M}$, it dissolves in the liquid mercury. At this point, the limiting current is dependent upon the concentration of $\mathrm{M}$ in the mercury drop. Since the volume of the mercury drop is much less than the volume of the cell, the concentration is increased. When the voltage is scanned in a positive direction, the metal is oxidized and returns to the solution. The peak current associated with the stripping step at a HMDE is given by the following equation 1

$$
i_{p}=2.72 \times 10^{5} n^{3 / 2} A D^{1 / 2} c v^{1 / 2}
$$

Where $\mathrm{n}$ is the number of electrons, $\mathrm{A}$ is the area of the electrode in $\mathrm{cm}^{2}, \mathrm{D}$ is the diffusion coefficient of $\mathrm{M}^{\mathrm{n}+}$ in $\mathrm{cm}^{2}$ second ${ }^{-1}$, $\mathrm{c}$ is the concentration of $\mathrm{M}^{\mathrm{n}+}$ in moles $\mathrm{cm}^{-2}$, and $v$ is the scan rate in volts second ${ }^{-1}$. 
The use of a mercury thin film electrode (MTFE) can also provide a further improvement in the sensitivity. With this electrode, a potential more negative than $\mathrm{E}^{0}$ of the mercuric ion $\left(\mathrm{Hg}^{2+}\right)$ is applied to a solution containing the ion. $\mathrm{Hg}^{2+}$ is reduced onto the electrode surface (usually glassy carbon, platinum, or gold) in the form of liquid mercury and the voltammetric experiment is conducted for the metal ion analyte using this film of liquid mercury as the working electrode. This electrode can provide better sensitivity than the HMDE because the volume of the mercury thin film is much less than that of the mercury drop. For a MTFE, the stripping current can be described as follows

$$
i_{p}=1.1157 \times 10^{6} n^{2} \text { Aclv }
$$

where $\mathrm{n}$ is the number of electrons, $\mathrm{A}$ is the area of the electrode in $\mathrm{cm}^{2}, \mathrm{c}$ is the bulk concentration of $\mathrm{M}^{\mathrm{n}+}$ in moles $\mathrm{cm}^{-3}, 1$ is the thickness of the MTF in $\mathrm{cm}$, and $v$ is the scan rate in $\mathrm{V} \mathrm{s}^{-1}$. Due to its sensitivity, the MTFE is widely used in trace metal analysis ${ }^{3}$.

\section{Differential Pulse and Square Wave Voltammetry}

The most widely used applications of stripping voltammetry incorporate either a differential pulse or a square wave voltage waveform during the stripping step. The excitation signal for differential pulse voltammetry (DPV) is shown in Figure 1a. The current is sampled at the beginning and end of each voltage pulse, and the change in current is then plotted as a function of the baseline potential as seen in Figure 1b. Since the Faradaic current is a function of $\mathrm{t}^{-1 / 2}$ and the charging current is a function of $\mathrm{t}^{-1 / 3}$, the charging current will decrease much more rapidly with time than the Faradaic current, 


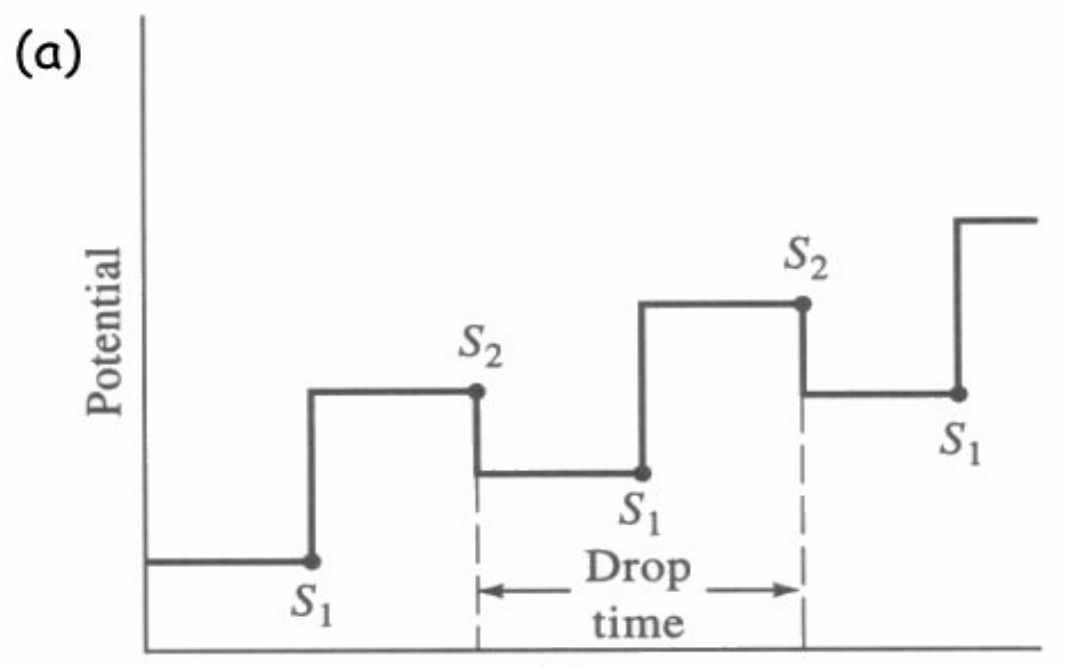

Time

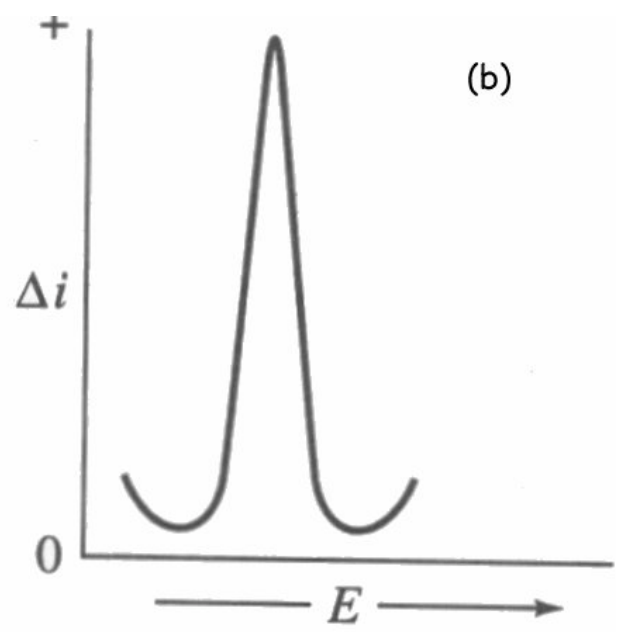

(c)
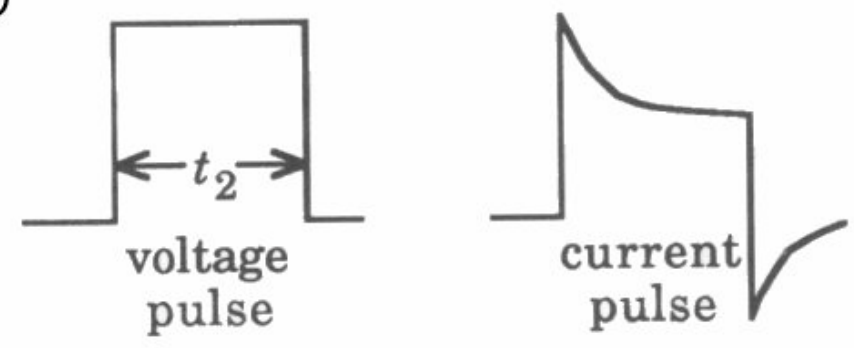

Figure 1. Differential Pulse Voltammetry. (a) the excitation signal for DPV; (b) the DPV voltammogram; (c) the voltage pulse and corresponding current pulse 
which allows the sensitivity of the method to be increased. The current as a function of time can be seen in Figure 1c. The current decays to the diffusion-limited current by the end of the pulse lifetime, thus any non-Faradaic contribution to the current is subtracted. At the beginning of the stripping scan, the baseline potential and the pulsed potential are both more negative than $\mathrm{E}^{0}$, so the change in current is essentially zero. As the pulsed potential reaches a value more positive than $\mathrm{E}^{0}$, the metal is oxidized, and when the pulse is over, it is again reduced. This affect greatly increases the sensitivity of the technique. The main limitation of DPV and DPASV is the speed of the analysis. This is due to the fact that DPASV was developed for use with a dropping mercury electrode. The technique was developed to change potential of each drop, so that several drops are needed to complete a scan. The common parameters associated with DPASV are given in Table 1.

For square wave voltammetry (SWV), a potential pulse is applied over a staircase waveform as seen in Figure 2. As in DPV, the net change in current is plotted, but the major difference between the two techniques is the speed of the analysis. This technique was originally developed as a way to perform a complete voltammogram on one drop when using a dropping mercury electrode 4 The development of this technique has improved with the use of computers which are capable of changing the parameters of the analysis and scanning the potential very quickly 5 . In square wave anodic stripping voltammetry (SWASV), the potential is held constant at a potential more negative than $\mathrm{E}^{0}$ of the metal for a constant time (deposition time), the potential is then swept positive 


\section{Table 1. Common Parameters of DPASV}

\begin{tabular}{|c|c|c|}
\hline Parameter & Description & Magnitude \\
\hline Pulse amplitude & $\begin{array}{l}\text { The magnitude of the potential } \\
\text { pulse }(\mathrm{mV})\end{array}$ & \pm 1 to \pm 200 \\
\hline Scan rate & $\begin{array}{l}\text { The rate of the potential scan } \\
\text { (mV/second) }\end{array}$ & 1 to 200 \\
\hline Sample width & $\begin{array}{l}\text { The time at which data points } \\
\text { are collected (milliseconds) }\end{array}$ & $\begin{array}{l}\text { Dependent upon the } \\
\text { instrument }\end{array}$ \\
\hline Pulse width & $\begin{array}{l}\text { The duration of the potential } \\
\text { pulse (milliseconds) }\end{array}$ & 3 to 1000 \\
\hline Pulse period & $\begin{array}{l}\text { The time to complete one } \\
\text { potential cycle (milliseconds) }\end{array}$ & 40 to 8000 \\
\hline $\begin{array}{l}\text { Deposition } \\
\text { potential }\end{array}$ & $\begin{array}{l}\text { The potential at which the } \\
\text { analyte is reduced onto the } \\
\text { electrode }(\mathrm{mV})\end{array}$ & $\begin{array}{l}\text { Dependent upon the } \\
\text { analyte }\end{array}$ \\
\hline
\end{tabular}




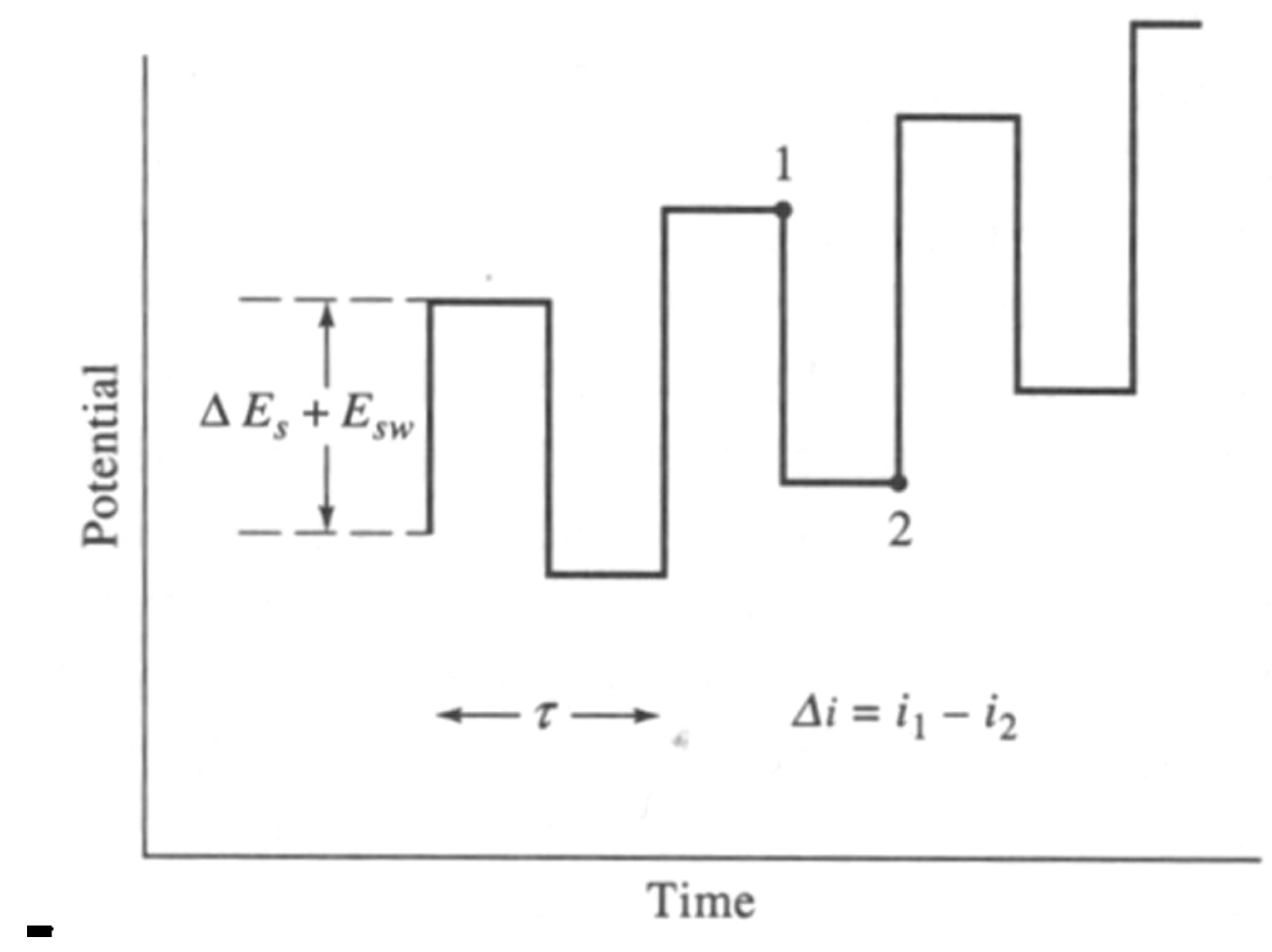

Figure 2. The Excitation Signal for OSWV. 
using the square waveform during the stripping step. The common parameters of the technique are shown in Table 2.

\section{Ultrasound}

The use of ultrasound refers to the emission of high frequency sound waves (15 kHz to $10 \mathrm{MHz}$ ) which do not interact directly with a molecular species; and when considering a liquid, the interaction is through cavitation and the formation of radicals. Cavitation is the formation, growth, and implosive collapse of bubbles in a liquid ${ }^{6}$ which can produce intense local heating and high pressures. These intense local conditions are thought to reach roughly $5000^{\circ} \mathrm{C}$ and 500 atmosphere 6 and can provide benefits for many aspects of chemistry. For example, ultrasound has been found to promote the synthesis of many different types of organic and inorganic molecules $9,10,11,12,13$, as well as to increase Faradaic current in the realm of electrochemistry 14,15$] 16,17,18,19,20$.

The process of acoustic cavitation involves at least three stages: nucleation, bubble growth, and bubble collapse. Nucleation, in a pure liquid, must occur at a "weak point" in the liquid, which are suspended particles and dissolved gases present in the solution. The growth of the bubble can occur through inertial effects (if the ultrasound is high-intensity) or through rectified diffusion, in which the dissolved gases present in the solution partition into the interior of the bubble. When this bubble reaches a size where the pressure outside is greater than the pressure inside, it can rapidly implode, and this compression of the gas generates heat. This is generally referred to as the "sonochemical hot spot." 


\section{Table 2. Common Parameters of OSWSV}

\begin{tabular}{|l|l|l|}
\hline Parameter & Description & Magnitude \\
\hline Square wave & $\begin{array}{l}\text { The magnitude of each pulse } \\
\text { with respect to the staircase } \\
\text { base potential (mV) }\end{array}$ & 1 to 250 \\
\hline Frequency & $\begin{array}{l}\text { The number of potential } \\
\text { cycles per second (Hz) }\end{array}$ & $\begin{array}{l}\text { Dependent upon } \\
\text { the number of } \\
\text { sampling points }\end{array}$ \\
\hline Sampling points & $\begin{array}{l}\text { Data collection at the end of } \\
\text { each half-cycle pulse }\end{array}$ & $\begin{array}{l}\text { Dependent upon } \\
\text { the instrument }\end{array}$ \\
\hline Step potential & $\begin{array}{l}\text { Potential step height for base } \\
\text { staircase waveform (mV) }\end{array}$ & 1 to 40 \\
\hline Deposition potential & $\begin{array}{l}\text { The potential at which the } \\
\text { analyte is reduced onto the } \\
\text { electrode (mV) }\end{array}$ & $\begin{array}{l}\text { Dependent upon } \\
\text { the analyte }\end{array}$ \\
\hline
\end{tabular}


Acoustic cavitation in a system which contains a solid-liquid interface is somewhat different from the process in a pure liquid. Here, the solid-liquid interface is the main site of nucleation; however, there are two additional processes which can occur at the interface. First, it has been found that bubble collapse at a surface is asymmetric. The cavitation process occurring at the solid surface sends a fast moving stream of liquid to the surface (microjets) $\sqrt{19}$. These microjets have been shown to pit glassy carbon electrode (GCE) surfaces 20 . Second, there is shock wave damage to the surface which is caused by shock waves generated by the rapid implosion at the surface ${ }^{6}$.

The damage caused to the solid surface by cavitation causes localized erosion to the surface; and this exposes clean, highly heated areas on the surface while actually ejecting certain metals from the surface of a metal electrode. In order for the microjet effect on the surface to be observed, the surface must be several times larger than the bubble size.

Electrochemisty has proven to be an excellent way to observe the effects of ultrasound in a system with a solid-liquid interface. It has been shown that in the presence of ultrasound, the current associated with a Faradaic process is increased $14,15,16,17,18,19,20$. Several physical mechanisms are possible to modify electrode processes. These are: 1) the enhancement of mass transport to and from the electrode surface due to cavitation in solution; 2) the continuous electrode activation; 3) the formation of radicals, ions, and other high-energy species; and 4) the ultrasonic mediation of chemical processes associated with heterogeneous electron transfer steps 21 . 
Several studies of the effect of ultrasound on heterogeneous electron transfer have been reported. Madigan and Coury 22 studied the electron transfer rate constants for the $\mathrm{Fe}\left(\mathrm{H}_{2} \mathrm{O}\right)_{6}{ }^{2+/ 3+}$ system. They conducted studies in the presence and absence of ultrasound, and with ultrasound in the presence of alumina particles. The electron transfer rate increased by $50 \%$ with ultrasound alone, but when alumina particles were added to the system, the rate increased 2.25 to 4.50 times. The increased rate was attributed to the increase in temperature at the electrode surface. This increase in temperature, in the presence of ultrasound alone, was attributed to the cavitational events which occurred at the electrode. When the alumina particles were added to the system, the temperature increase at the electrode surface was much higher due to the collision of particles with the electrode surface. In both cases, the increased rate was considered to be due to the temperature increase at the electrode surface, and not to the effect of ultrasound on the actual electron transfer. The relative standard deviation (RSD) for the limiting currents was $3.1 \%$, while the RSD of the rate constant was much larger at $22.9 \%$. This indicated that the process responsible for the mass transfer enhancement was different from the process responsible for the increased currents at the electrode surface. The process which was responsible for the enhancement of electron transfer rates was thought to be cavitational events at the electrode surface. A problem with this conclusion, as cited by Birkin and Silva-Martine $\mathrm{z}^{23}$ is that no shift of $\mathrm{E}^{0}$ was seen for the redox couple studied. There should be a shift of $\mathrm{E}^{0}$ with temperature according to the following equation:

$$
\frac{\partial E^{0}}{\partial T}=\frac{S_{\text {react }}^{0}}{n F}
$$


where $\mathrm{T}$ is the temperature, $\mathrm{S}_{\text {react }}^{0}$ is the entropy of the reactant species, $\mathrm{n}$ is the number of electrons transferred, and F is Faraday's constant.

Birkin and Silva-Martine 23 did not observe a temperature change when they used sampled voltammetry at microelectrodes to examine the effect of ultrasound on the kinetics of electron transfer. With the use of sampled voltammetry at microelectrodes, each cavitational event could be observed since the bubble size is greater than the size of the microelectrode. First, each potential was scanned and the current was monitored with the assumption that the maximum current at each potential corresponds to a cavitational event. The maximum current at each potential was then plotted as a function of potential. They obtained rate constants for several redox couples. All rate constants in the presence of ultrasound agreed with those obtained without ultrasound present. They observed no rate increase due to the increase in temperature.

While there is a consensus that the main effect ultrasound has on current is through mass transport enhancement, there is some debate as to the process which contributes more to mass transport. The two processes thought to be responsible for enhancing mass transport are acoustic streaming and cavitational events at the electrode surface. Acoustic streaming refers to the generation of a beam of liquid by the ultrasonic horn 24 . This beam of liquid is directed at the electrode in the normal sonovoltammetric cell in which the electrode surface and the ultrasonic horn face each other ("face-on" geometry). The effect of acoustic streaming on mass transport has been studied by Compton et al.14, who studied the mass transport effect of sonication with several different electrode-horn geometries. The geometries utilized were the common "face-on" 
geometry (as described above), the "side-on" geomety in which the ultrasonic tip lies parallel to the electrode, and the sonotrode geometry in which the electrode is embedded in the ultrasonic tip. They proved that, in the face-on goemetry, the system behaves like a wall-jet voltammetric system. In this system, a laminar flow of liquid comes from a tube and hits the electrode. This flow in the presence of ultrasound is the acoustic stream. Compton et al 25 also found that the diffusion layer thickness in a voltammetric cell with ultrasound present is proportional to $\mathrm{D}^{2 / 3}$, which is observed with other techniques which involve hitting the electrode with a stream of liquid, namely tube, channel, and wall-jet voltammetry.

The chief cavitational event which is thought to contribute to mass transport is the formation of microjets near or at the electrode surface due to the collapse of bubbles. Acoustic streaming is thought to be a steady state component of ultrasound, while the microjets are thought to be a transient component. Degrand et al 14 conducted experiments with ultrasound at microelectrodes and showed that a steady state component and a transient component were present. Their voltammograms suggested that the transient component contributed more to the mass transport of the system than the steady state component. They obtained voltammograms at the microelectrode in which cavitational events were seen as oscillations in the signal. It was seen that the oscillations formed over a voltammogram. This "minimum" voltammogram is the steady state component, while the oscillations are the transient component. From the voltammograms, it was seen that the oscillations reach their own plateau, and increase the current much more than the steady state component. 
Coury and Cooper ${ }^{18}$ divided the two ultrasound components of the current into a time-dependent and a time-independent component. The time-dependent component was assumed to be a result of cavitational events and the time-independent component was assumed to be due to acoustic streaming. They observed that the time-independent component was the steady state component and was linear with concentration. The timeindependent component was seen as an oscillation in the limiting current, or the deviation in the limiting current, and when this deviation was plotted against concentration, it was also found to be linear.

The main problem with the use of ultrasound in electroanalytical chemistry appears to be a "roughening" effect on electrode surfaces. Compton et al 21 examined the effect of ultrasound on platinum and aluminum electrodes using atomic force microscopy (AFM). Both of these materials showed erosion effects with an ultrasound power of 60 $\mathrm{W} \mathrm{cm}{ }^{-2}$. The platinum electrode appeared to have surface damage after 120 seconds of sonication with the horn positioned $10 \mathrm{~mm}$ above the electrode surface. The aluminum electrode showed comparable erosion after 300 seconds of sonication with a horn distance of $30 \mathrm{~mm}$. Coury and Zhang ${ }^{20}$ showed that ultrasound can severely pit a glassy carbon surface after sonication for 5 minutes. Coury et al 26 actually used sonication to prepare microarray electrodes by coating electrodes with a polymer, and then sonicating the electrode to blast small holes in the polymer. This was done at electode-sonicator tip distance of $2 \mathrm{~mm}$.

Despite this potential erosion problem, the use of ultrasound for mass transport in electrochemical experiments has been reported to be successful. Compton et al 27 applied 
the technique to the detection of lead in wine. A platinum supported-mercury thin film electrode (Pt-MTFE) was used and the only sample preparation required was acidification. The total lead content was $22( \pm 6) \mu \mathrm{g} \mathrm{L}{ }^{-1}$ for pure wine, which was comparable to that obtained using atomic absorption spectroscopy (AAS); however, the relative standard deviation (RSD) of their measurements was $27 \%$. Brett et al. $\stackrel{28}{\text { found }}$ that a glassy carbon-mercury thin film electrode (GC-MTFE) seemed to be stable when covered with a Nafion membrane. The limit of detection for both $\mathrm{Pb}^{2+}$ and $\mathrm{Cd}^{2+}$ was found to be $3 \times 10^{-11} \mathrm{M}$ when mercury was plated in situ with an RSD of $1.2 \%$. The first measurement was not included in any statistical evaluation. However, if mercury was not plated in-situ, they found that the signal decreased by 3 to $10 \%$ after 10 measurements. This is probably due to the MTF not being stable for any valuable length of time in the presence of ultrasound. They also found that the mercury droplets closer to the edge of the electrode were much larger than those in the center of the electrode. They attributed

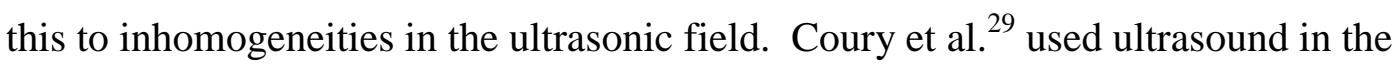
preconcentration step of abrasive stripping voltammetry. In this process, a gold electrode was placed in a slurry of metal particles. Ultrasound was then applied and the metal particles were melted onto the electrode. The electrode was then placed into another solution and the metal particles were stripped. In adsorptive stripping voltammetry (AdSV), the preconcentration step consists of an interfacial accumulation of the target onto an electrode surface 30 . Compton and Agra-Gutierrez used ultrasound in the preconcentration step of this technique ${ }^{30}$, and showed that the presence of ultrasound did 
not increase the sensitivity, but instead increased the rate at which the adsorption equilibrium is reached.

\section{Goals}

The benefits as well as the problems associated with the use of ultrasound with electrochemisty have been outlined above. The goal of this research is to balance the enhanced mass transport effects with the surface erosion effects in order to develop a technique which is both sensitive and reproducible. To this end, a technique which couples square wave anodic stripping voltammetry (SWASV) with ultrasound where the MTF is mercury-plated before any voltammetric experiment. This system could ultimately be used to obtain formation constants of metals and natural ligands which are important to aquatic systems. In order to achieve this, the electrode will be covered with a dialysis membrane so that only the free metal concentration is measured. The ultrasound should enable the analyte to reach equilibrium across the membrane more rapidly than techniques such as stirring and electrode rotation. 


\section{CHAPTER II}

\section{THE PLATINUM ELECTRODE}

\section{Introduction}

Zhang and Coury have reported that severe pitting of a glassy carbon electrode (GCE) surface can occur in the presence of ultrasound 20 , and that the surface of platinum (Pt) electrodes appreared to "roughen"21. Compton et al 27 reported that the Pt-MTFE when used with ultrasound was suitable for the detection of lead in wine at a concentration of $22 \mu \mathrm{g} \mathrm{L}^{-1}$; however, the RSD was only $27 \%$. Compton et al $\stackrel{31}{\text { also used }}$ a Pt-MTF sonotrode to detect lead because they found that mercury did not adhere well enough to glassy carbon to be used in the study. As a result of these studies, my initial experiments were conducted with Pt electrodes in the hope that mercury would adhere to this electrode in the presence of ultrasound.

\section{Experimental}

Apparatus

A BAS-100 Electrochemical Analyzer (BAS, West Lafayette, IN) was used throughout. The Pt electrode (Pine Instrument Co., Grove City, PA) had a diameter of $7.215 \mathrm{~mm}$. The ultrasonic processor used was a Heat Systems, Inc. Model XL2020 (Farmingdale, NY). In all ultrasound experiments, an ultrasonic microtip with a diameter of $3.585 \mathrm{~mm}$ was positioned at the top of the cell with the electrode positioned at the bottom of the cell as shown in Figure 3. The electrode was held in place by a threaded teflon "cap" which had a circular hole (19 mm diameter) cut in the middle. Two 


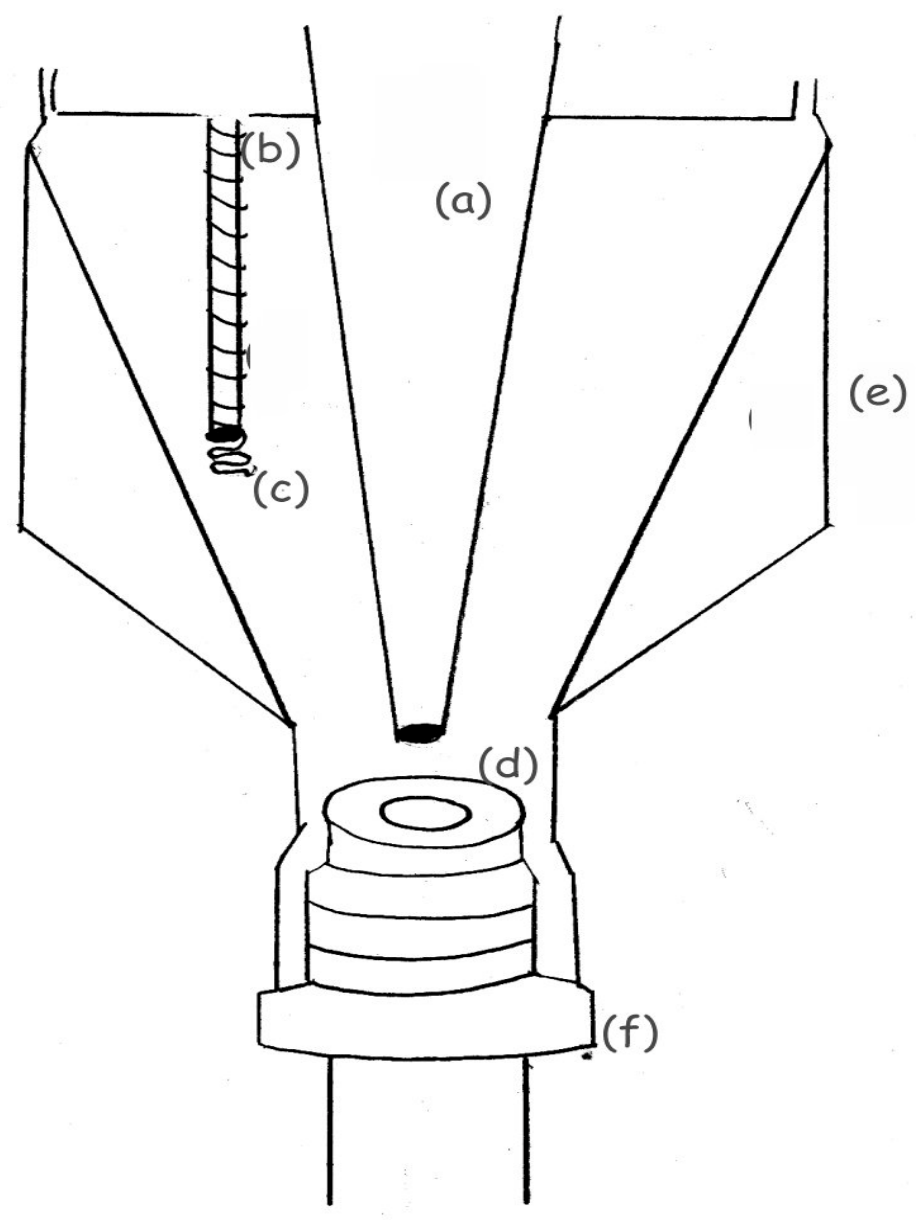

Figure 3. The Electrochemical Cell. (a) ultrasonic tip; (b) reference electrode; (c) auxiliary electrode; (d) working electrode; (e) cool water jacket; (f) "cap" 
"O" rings were fitted into grooves cut inside the cap. One groove was located $5 \mathrm{~mm}$ from the top of the cap to prevent leakage and to hold the electrode in place, and the other was $2 \mathrm{~mm}$ from the bottom. This cell configuration allowed the ultrasound tip-to-electrode distance to be easily varied by simply sliding the electrode along the cap, which ensured that the immersion distance of the ultrasonic tip within the cell was kept constant. The cell volume was always $50 \mathrm{~mL}$. A Fisher Scientific Model 73 constant temperature immersion circulator was used with ultrasonic equipment.

The Pt electrode was polished before each experiment using Fisherbrand alumina suspensions. The electrode was initially polished with a $0.3 \mu \mathrm{m}$ suspension and the final polishing done with a $0.05 \mu \mathrm{m}$ suspension. After polishing, the electrode was rinsed with water and placed in a sonic bath to make certain that all residue was removed.

\section{Reagents and Solutions}

A $0.100 \mathrm{M} \mathrm{KNO}_{3}$ solution was prepared from Fisher Reagent Grade $\mathrm{KNO}_{3}$. This was used to prepare the $0.0100 \mathrm{M} \mathrm{KNO}_{3}$ solution used as the supporting electrolyte in all studies. An ACS Certified 1000-ppm $\mathrm{Hg}\left(\mathrm{NO}_{3}\right)_{2}$ Atomic Absorption (AA) Standard (Fisher Scientific) diluted to $1.0 \times 10^{-3} \mathrm{M}$ with $0.0100 \mathrm{M} \mathrm{KNO}_{3}$ was used to deposit the

mercury on the Pt electrode. A 100-ppm stock solution of $\mathrm{Cd}^{2+}$ was prepared by dilution from a 1000-ppm AA standard (Fisher Scientific). All pH adjustments were made by using a 5\% $\mathrm{NaOH}$ solution. All solutions were prepared with double glass-distilled water which had been passed through a deionizer (Fisher, Ultrapure). All solutions were deaerated for at least ten minutes with $\mathrm{N}_{2}$ prior to electrochemical experiments. 
Dialysis Membrane

The membranes employed were cut from Spectra/Por 6 cellulose dialysis tubing (Spectrum Medical Industries Inc.), which had a molecular weight cutoff of 1000. The tubing was soaked in $70^{\circ} \mathrm{C}$ deionized water for at least twenty minutes then thoroughly rinsed with deionized water at room temperature. The membrane was soaked in deionized water for at least 48 hours prior to use. Fresh tubing was prepared weekly, with the membrane stored via manufacturer's instructions. The membrane was attached to the electrode with a rubber "O" ring via a small groove cut in the teflon surrounding the Pt electrode. Several drops of $0.0100 \mathrm{M} \mathrm{KNO}_{3}$ solution were placed between the electrode and the membrane.

Mercury Plating and Electrode Preconditioning

For all studies without a membrane, the freshly polished Pt electrode was placed in $50 \mathrm{~mL}$ of $1 \times 10^{-3} \mathrm{M} \mathrm{Hg}\left(\mathrm{NO}_{3}\right)_{2}$. The $\mathrm{pH}$ of the mercuric solution was 1.35 to 1.40 unless otherwise stated. The solution was purged with $\mathrm{N}_{2}$ for at least ten minutes and the MTF was then plated at a potential of $-500 \mathrm{mV}$ vs. $\mathrm{Ag} / \mathrm{AgCl}$ reference electrode, while either stirring with $\mathrm{N}_{2}$ or applying ultrasound. For the membrane-covered mercury thin film electrode (MCMTFE), the MTF was plated in the same manner unless otherwise stated. 
Procedure

All analyses were conducted using Osteryoung Square Wave Stripping Voltammetry (OSWSV). The instrumental parameters used for all OSWSV experiments are summarized in Table 3. All additions to the analyte solutuion were made using Eppendorf micropipets with disposable tips. Additions were made from a 100-ppm $\mathrm{Cd}^{2+}$ solution. All polarographic cells were rinsed with dilute $\mathrm{HNO}_{3}$ and deionized water prior to use. The MTFE was also preconditioned (quiet runs) with the same parameters outlined in Table 3. The metal-ion deposition time was 30 seconds during all quiet runs. The ultrasound tip-to-electrode distance was varied by adjusting the electrode so that the extension of the ultrasound tip in the solution was constant. Convection was supplied either via $\mathrm{N}_{2}$ stirring with the stir tube located on the bottom of the cell or ultrasound.

\section{The Pt-MTFE}

The peak current for the Pt-MTFE increased with successive voltage scans until a plateau was reached, and the results for 23 successive scans are shown in Figure 4 . The Pt electrode was plated with mercury while stirring with $\mathrm{N}_{2}$, and the deposition of $\mathrm{Cd}^{2+}$ was also conducted while stirring with $\mathrm{N}_{2}$. Another experiment was conducted in order to determine if this "plateau" effect would occur with subsequent additions of $\mathrm{Cd}^{2+}$. The results are shown in Figure 5 and the "plateau" effect was indeed observed after each increase in the $\mathrm{Cd}^{2+}$ concentration. The current at $80 \mathrm{ppb} \mathrm{Cd}^{2+}$ was twice that seen at 40 ppb as expected, but the reason for the "plateau" effect is unclear. The current did appear to reach the plateau in a shorter number of runs. 
Table 3. Experimental Parameters Used for OSWSV

\begin{tabular}{|l|l|}
\hline Parameter & Magnitude \\
\hline Deposition potential & $-900 \mathrm{mV}$ \\
\hline Final potential & $-300 \mathrm{mV}$ \\
\hline Sensitivity & $1.0 \times 10^{-5}$ \\
\hline Deposition time & 30 to 180 seconds \\
\hline Square wave amplitude & $50 \mathrm{mV}$ \\
\hline Frequency & $50 \mathrm{~Hz}$ \\
\hline Quiet time & $10 \mathrm{~seconds}$ \\
\hline Sampling points & 256 \\
\hline Step potential & $4 \mathrm{mV}$ \\
\hline
\end{tabular}




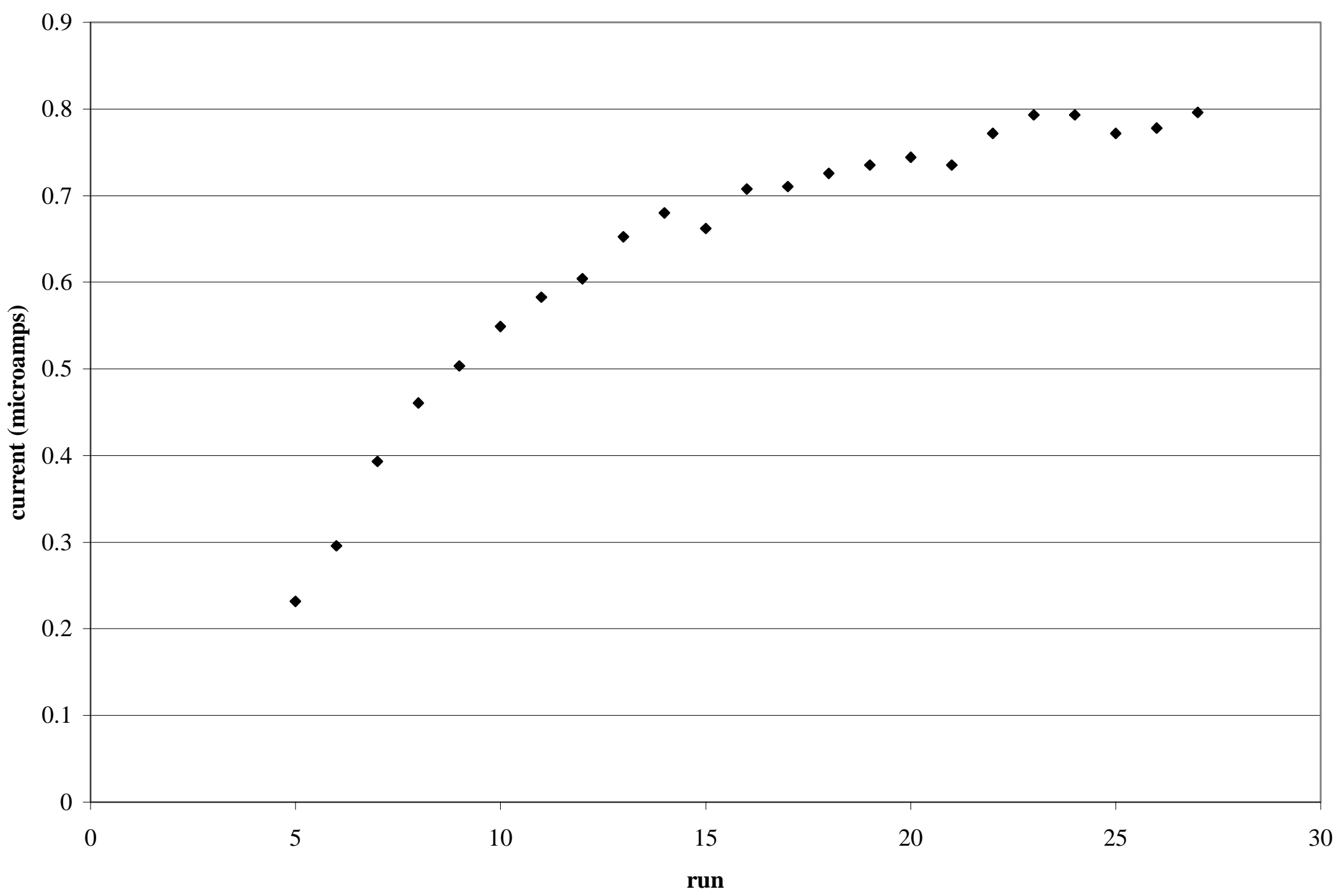

Figure 4. Behavior of the Pt-MTFE: $\left[\mathrm{Cd}^{2+}\right]=40 \mathrm{ppb}$; deposition time $=60$ seconds. 


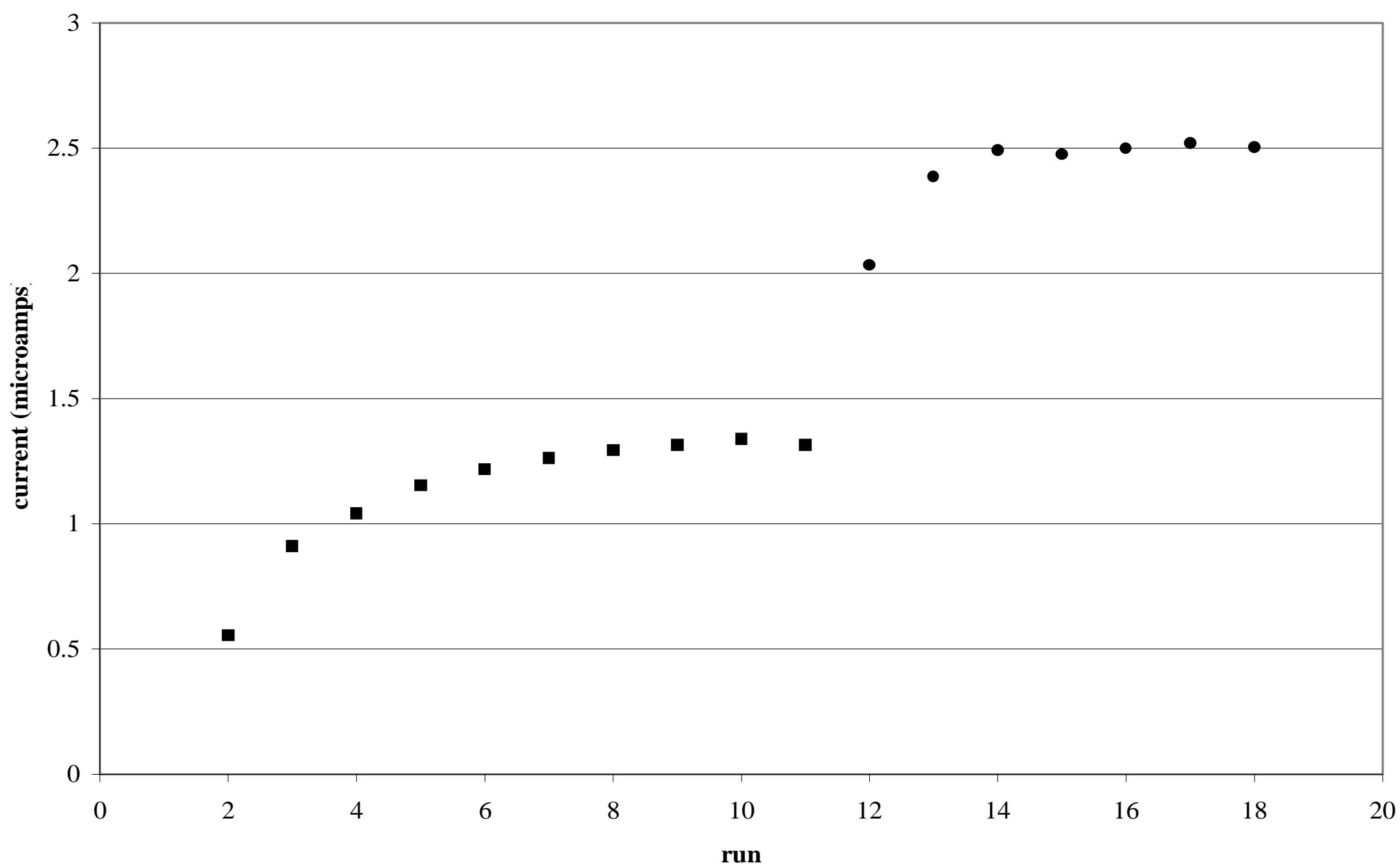

Figure 5. Effect of Multiple Injections on the Pt-MTFE: deposition time $=60$ seconds. $\square\left[\mathrm{Cd}^{2+}\right]=40 \mathrm{ppb}, \boldsymbol{O}\left[\mathrm{Cd}{ }^{2+}\right]=80 \mathrm{ppb}$ 


\section{Effect of Ultrasound on Current}

Since ultrasound was shown previously to increase current by increasing the mass transpor $14,15,16,17,18,19,20$ experiments were conducted to examine this effect at the PtMTFE. Stripping currents obtained with ultrasound deposition of $\mathrm{Cd}^{2+}$ were compared to those obtained using $\mathrm{N}_{2}$ stirring during deposition (Figures 6, 7, and 8). The MTFE was mercury-plated while $\mathrm{N}_{2}$-stirring. The $\mathrm{Cd}^{2+}$ concentration was $40 \mathrm{ppb}$ when ultrasound was used in the deposition step, and $80 \mathrm{ppb}$ when $\mathrm{N}_{2}$ stirring was employed during deposition. It is clearly seen that ultrasound enhanced the Faradaic current at any ultrasound distance, although Cooper and Coury $\sqrt{18}$ previously reported that an increase in current did not occur until their electrode was located $5 \mathrm{~mm}$ or less from the ultrasonic tip.

\section{Effect of Ultrasound on MTF plating}

Several studies have coupled ultrasound with voltammetry at the MTFE where the mercury was plated in situ 27,3$]$; however, none have been successful for the measurement of a metal when the MTF was plated ex-situ. For studies of trace metal speciation, the mercury and the target metal ion must be deposited separately, so ex-situ plating is essential.

Studies were conducted to compare the effect of ultrasound tip-to-electrode distances on ex-situ MTF plating. The MTF was plated with the ultrasonic tip located 5, 10, and $15 \mathrm{~mm}$ from the electrode. The results of the distances during MTF plating and the current obtained during cadmium analysis are shown in Figures 9 and 10. As seen in Figure 10, the maximum current obtained for $\mathrm{Cd}^{2+}$ at each plating distance is linear with 


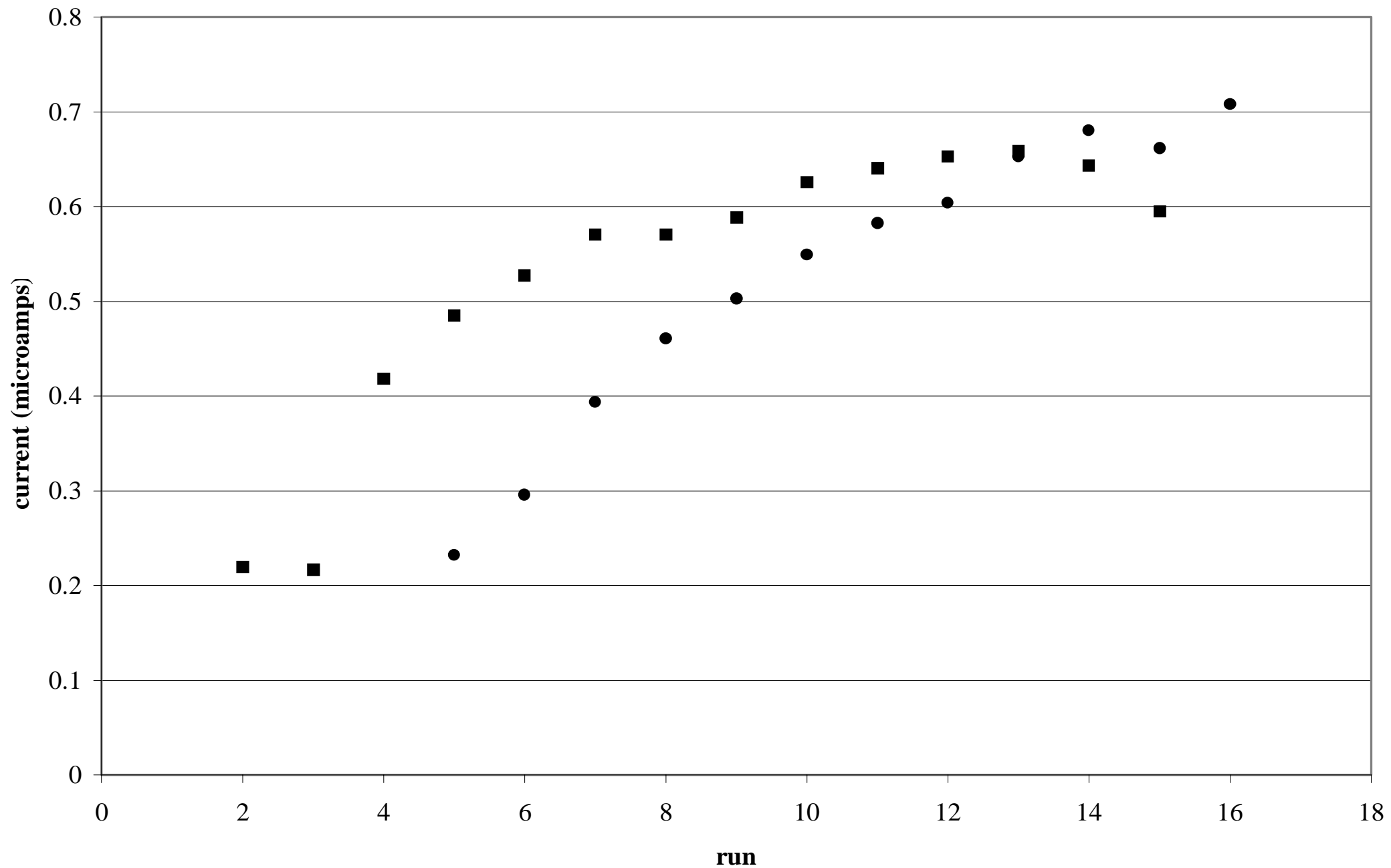

Figure 6. The Effect of Ultrasound on Current: deposition time $=60$ seconds. Ostir $\mathrm{w} /\left[\mathrm{Cd}^{2+}\right]=80 \mathrm{ppb}, \square 15 \mathrm{~mm} \mathrm{w} /\left[\mathrm{Cd}{ }^{2+}\right]=40 \mathrm{ppb}$ 


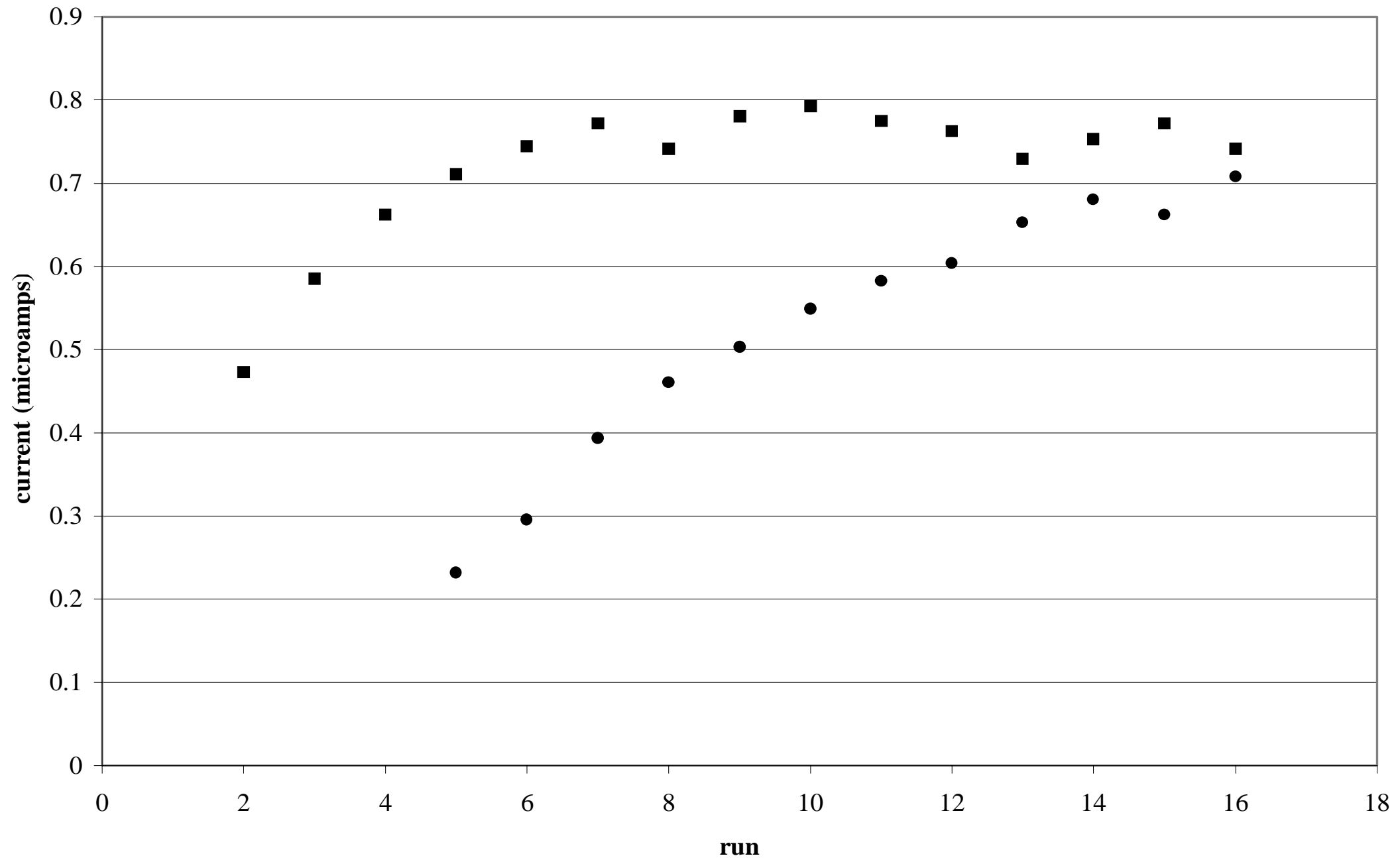

Figure 7. The Effect of Ultrasound on Current: deposition time $=60$ seconds. $\mathrm{stir} w /\left[\mathrm{Cd}^{2+}\right]=80 \mathrm{ppb}, \mathbf{\square} 10 \mathrm{~mm} \mathrm{w} /\left[\mathrm{Cd}^{2+}\right]=40$ ppb 


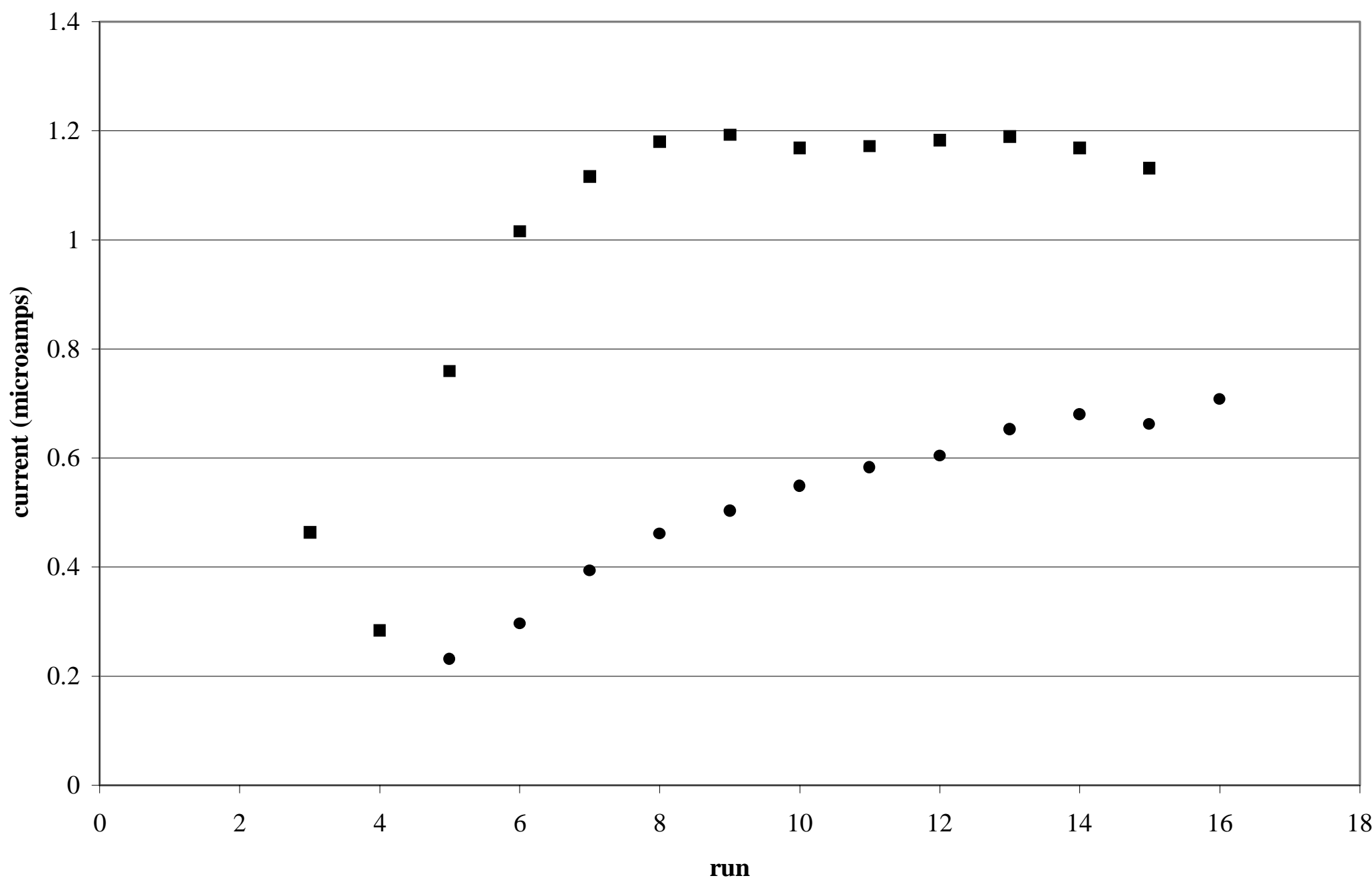

Figure 8. Effect of Ultrasound on Current: deposition time $=60$ seconds. $\mathrm{stir} w /\left[\mathrm{Cd}^{2+}\right]=80 \mathrm{ppb}, \boldsymbol{\square} \mathrm{mm} \mathrm{w} /\left[\mathrm{Cd}{ }^{2+}\right]=40 \mathrm{ppb}$ 


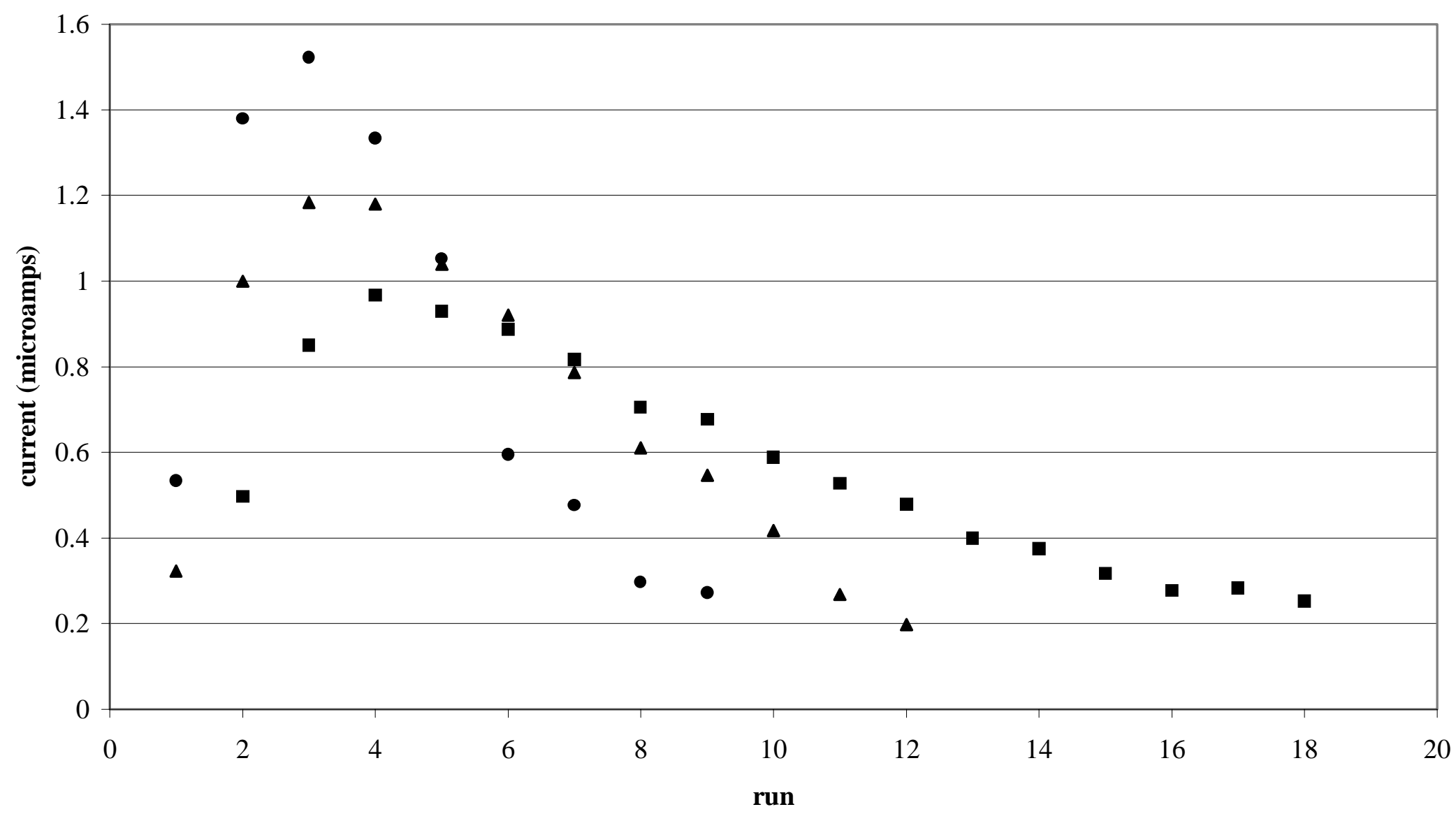

Figure 9. The Effect of Ultrasound Distance on Plating a MTF Onto Pt: MTF plated with ultrasound at 5, 10, and $15 \mathrm{~mm}:\left[\mathrm{Cd}{ }^{2+}\right]=$ $40 \mathrm{ppb}$; deposition time $=60$ seconds; analysis distance $=10 \mathrm{~mm}$. MTF plated at $5 \mathrm{~mm}, \boldsymbol{\Delta}$ MTF plated at $10 \mathrm{~mm}, \boldsymbol{M T F}$ plated at 15 $\mathrm{mm}$ 


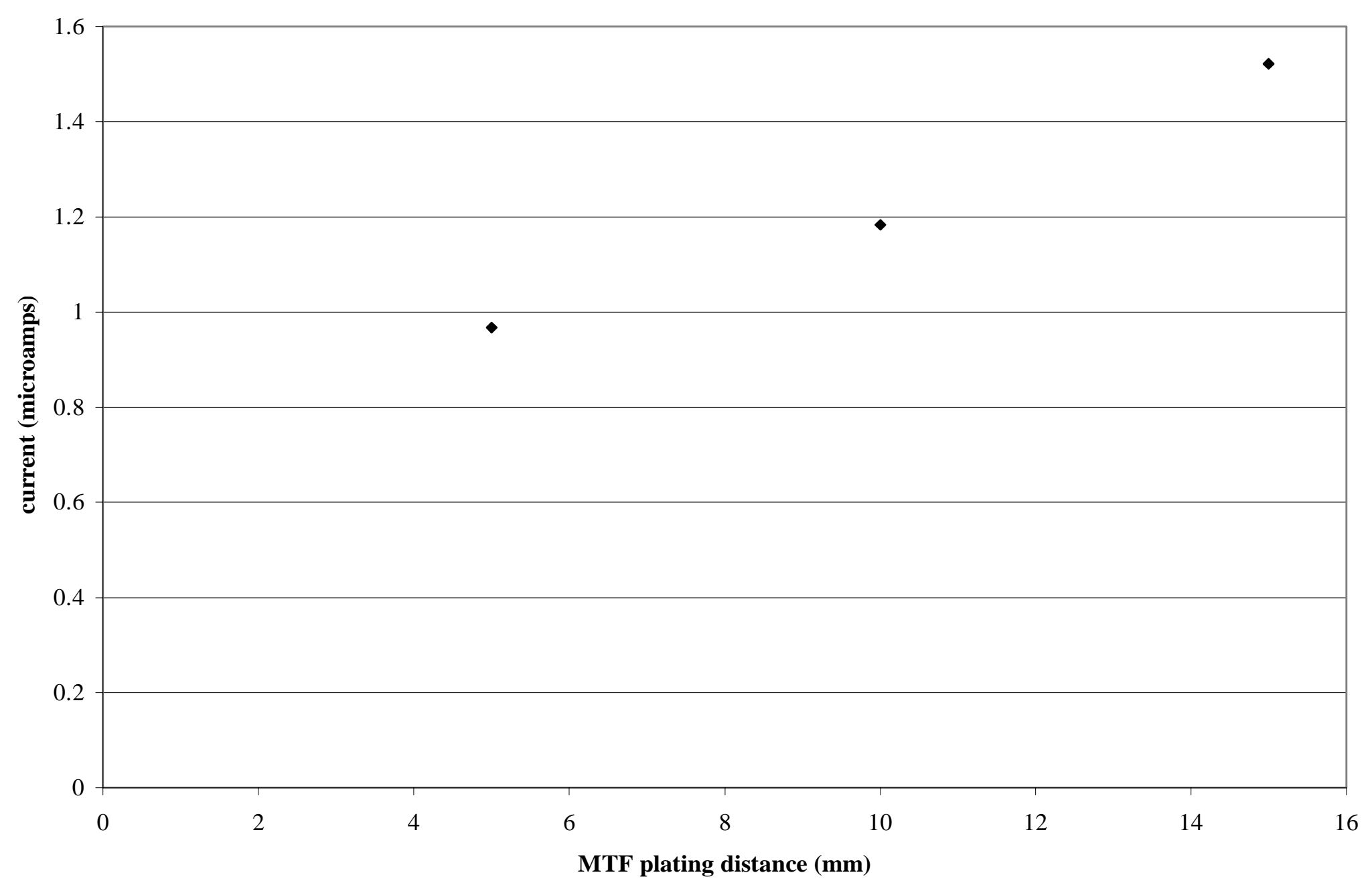

Figure 10. The Effect of Ultrasound Distance On Plating MTF Onto Pt: current vs. ultrasound MTF plating distance from Figure 9. 
The MTF plating distance. MTF plating in the presence of ultrasound was also compared to a MTF plated in the presence of $\mathrm{N}_{2}$-stirring. The results are seen in Figures 11-14. As seen in Figure 14, $\mathrm{N}_{2}$-stirring is a more efficient way of plating the MTF onto platinum. The results seen in Figure 13 suggest that the MTF plated while $\mathrm{N}_{2}$-stirring is also more

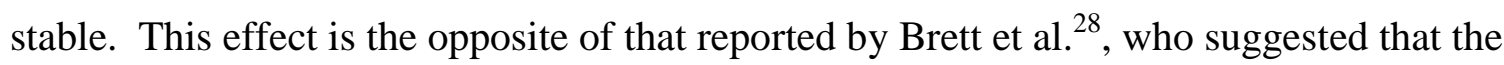
mercury droplets formed with ultrasound were smaller and farther apart than those formed using batch injection analysis (BIA) in which a microliter sample of a $\mathrm{Hg}^{2+}$ solution is injected onto the center of the electrode. They assumed that the droplets formed with BIA would be less stable in the presence of ultrasound than those formed with ultrasound because the mechanical destruction due to ultrasound should be massdependent. However, in our case this does not seem to be true as seen in Figure 9.

The current increased at the shorter plating times. Since the volume of the MTF will decrease with plating time, the concentration of cadmium within a given MTF should increase as we have observed (Figure 14). To investigate if Hg-plating in the presence of ultrasound is similar, the MTF was plated with ultrasound located $15 \mathrm{~mm}$ from the electrode, and the results of this study are shown in Figures 15 and 16. As one can see, the effect is similar with ultrasound; however, the MTF still seems to be unstable.

\section{The Pt-MCMTFE}

When the Pt electrode was covered with a 1000 molecular weight cut-off (MWCO) membrane and the MTF was plated with mercury under normal conditions, a bubble always appeared over the electrode surface which led to erratic results. The 


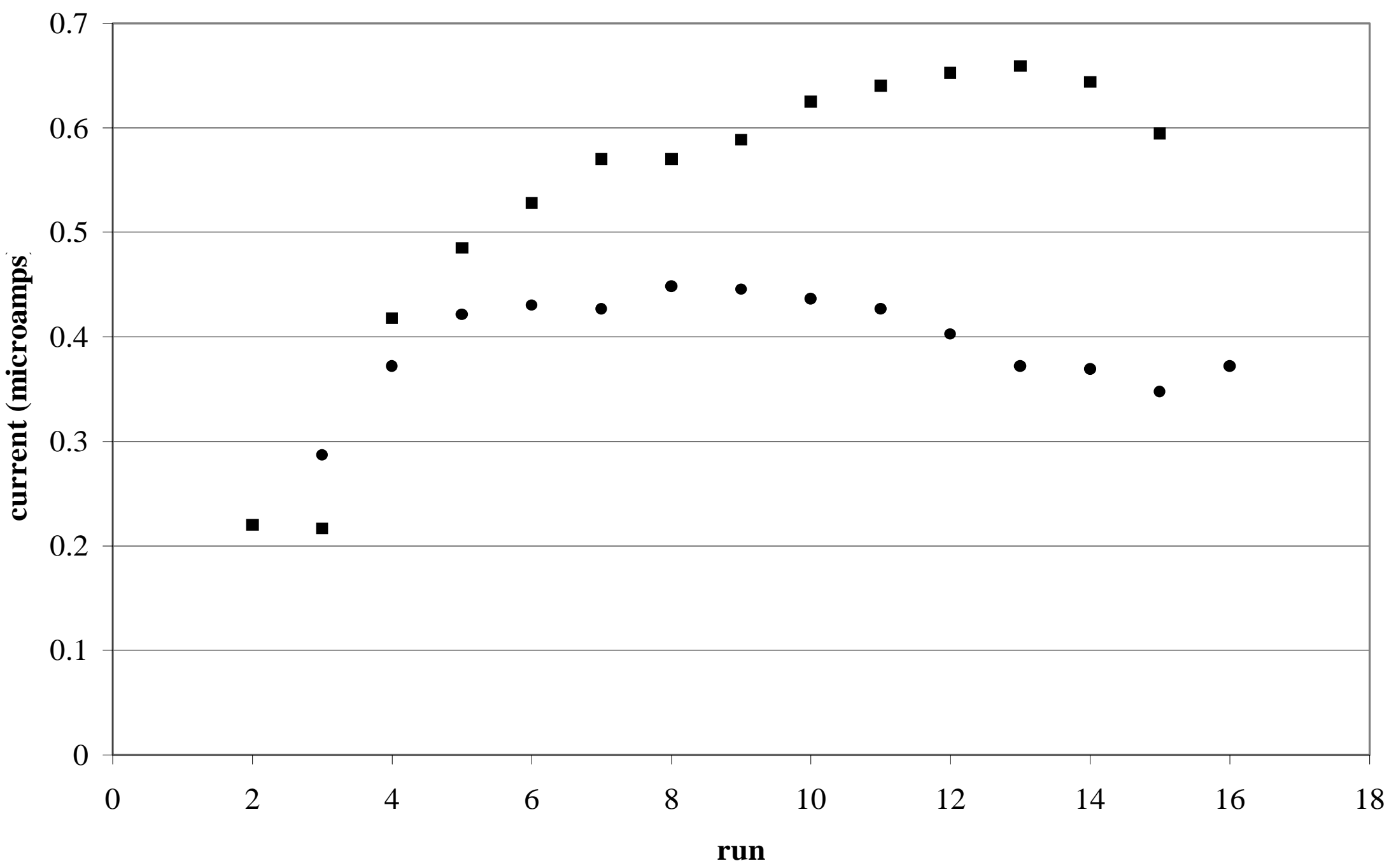

Figure 11. Comparison of MTF Plated While Stirring and One Plated With Ultrasound at 15 mm: $\left[\mathrm{Cd}^{2+}\right]=40 \mathrm{ppb}$; deposition time $=60$ seconds; analysis distance $=15 \mathrm{~mm}$. OMTF plated w/ ultrasound, $\mathbf{M T F}$ plated w/ stir 


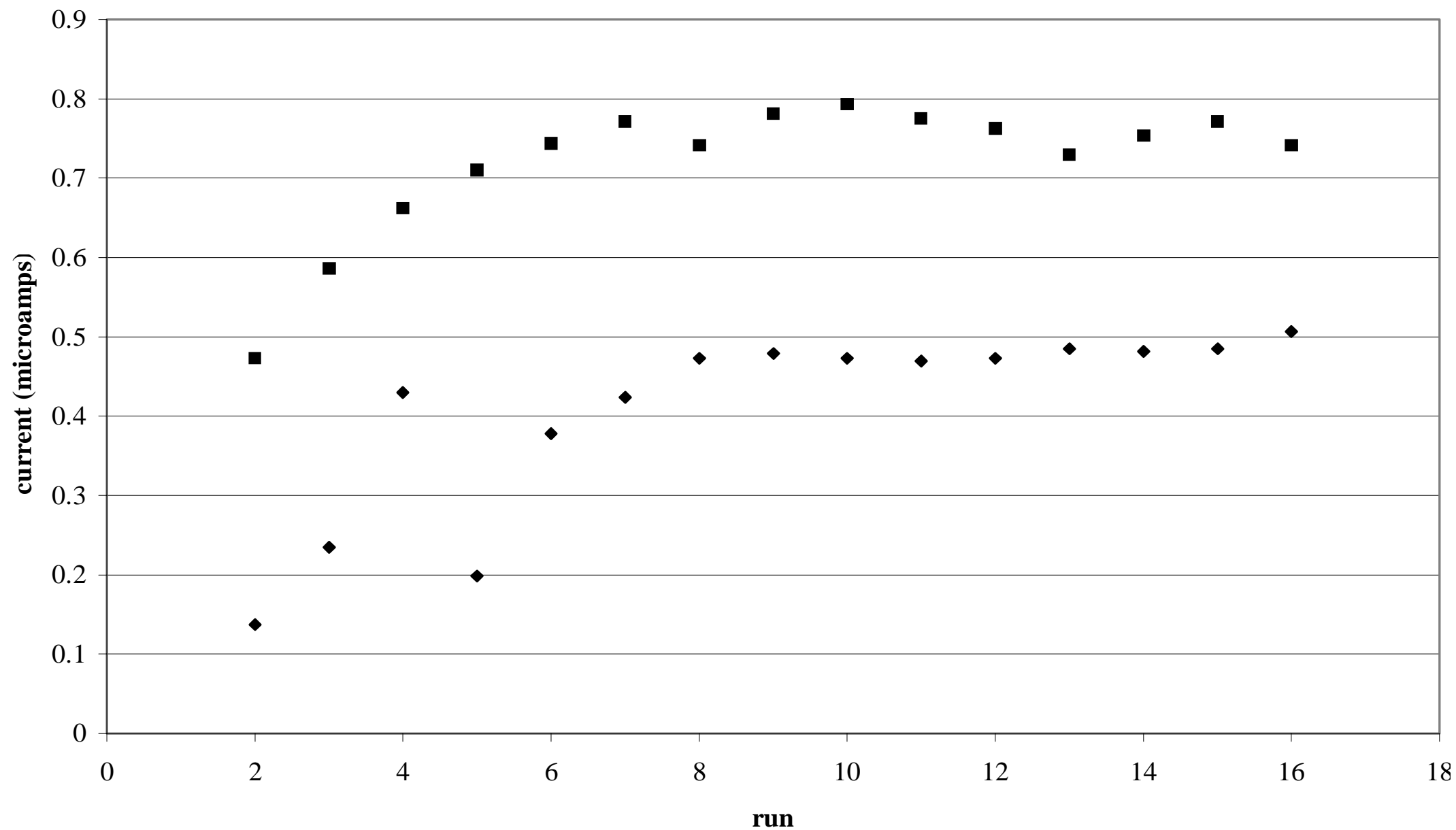

Figure 12. Comparison of MTF Plated While Stirring and One Plated With Ultrasound at 15 mm: $\left[\mathrm{Cd}^{2+}\right]=40 \mathrm{ppb}$; deposition time $=60$ seconds; analysis distance $=10 \mathrm{~mm}$. $\diamond$ MTF plated $\mathrm{w} /$ ultrasound, $\mathbf{M T F}$ plated $\mathrm{w} / \mathrm{stir}$ 


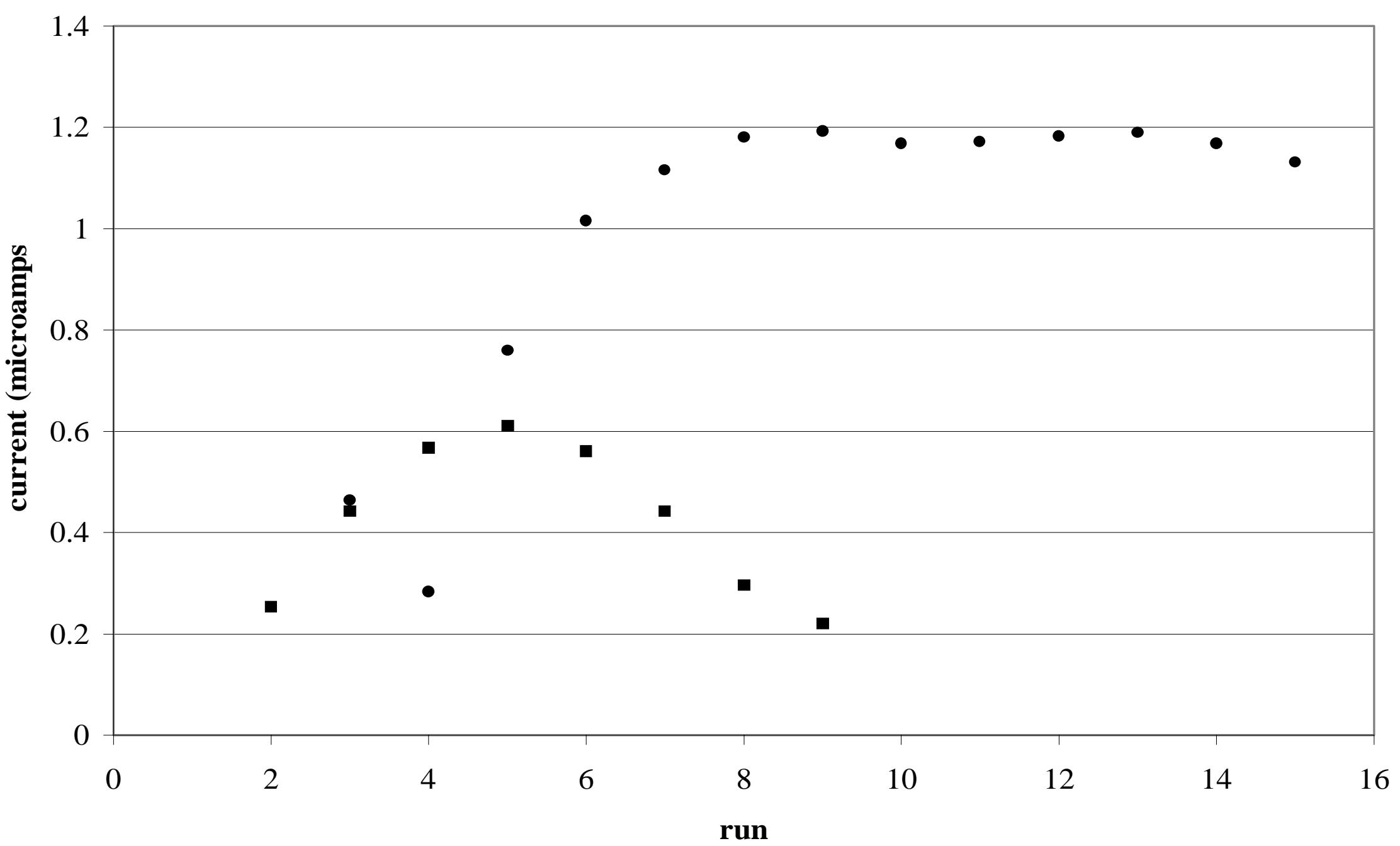

Figure 13. Comparison of MTF Plated While Stirring and One Plated With Ultrasound at $\mathbf{1 5}$ mm: $\left[\mathrm{Cd}^{2+}\right]=40 \mathrm{ppb}$; deposition time $=60$ seconds; analysis distance $=5 \mathrm{~mm}$. MTF plated w/ ultrasound, MTF plated $\mathrm{w} / \mathrm{stir}$ 


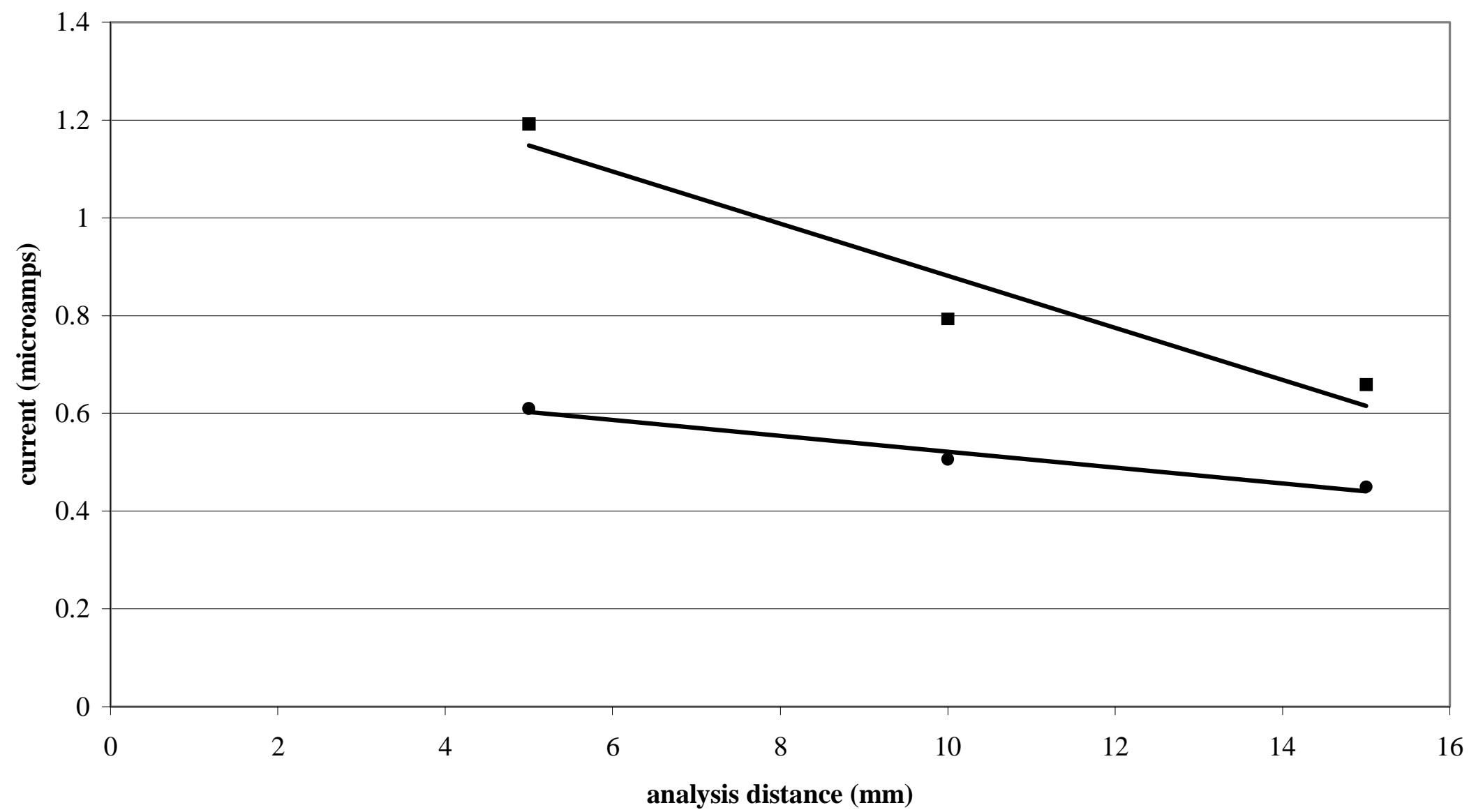

Figure 14. Maximum Current vs. Ultrasound Tip-to-Electrode Distance During Cadmium Analysis: comparison of MTF plating while $\mathrm{N}_{2}$-stirring and while using ultrasound at $15 \mathrm{~mm}$ using data from Figures 11-13. $\boldsymbol{\square}$ MTF plated w/ stirring, $\boldsymbol{O}$ MTF plated w/ ultrasound at $15 \mathrm{~mm}$ 


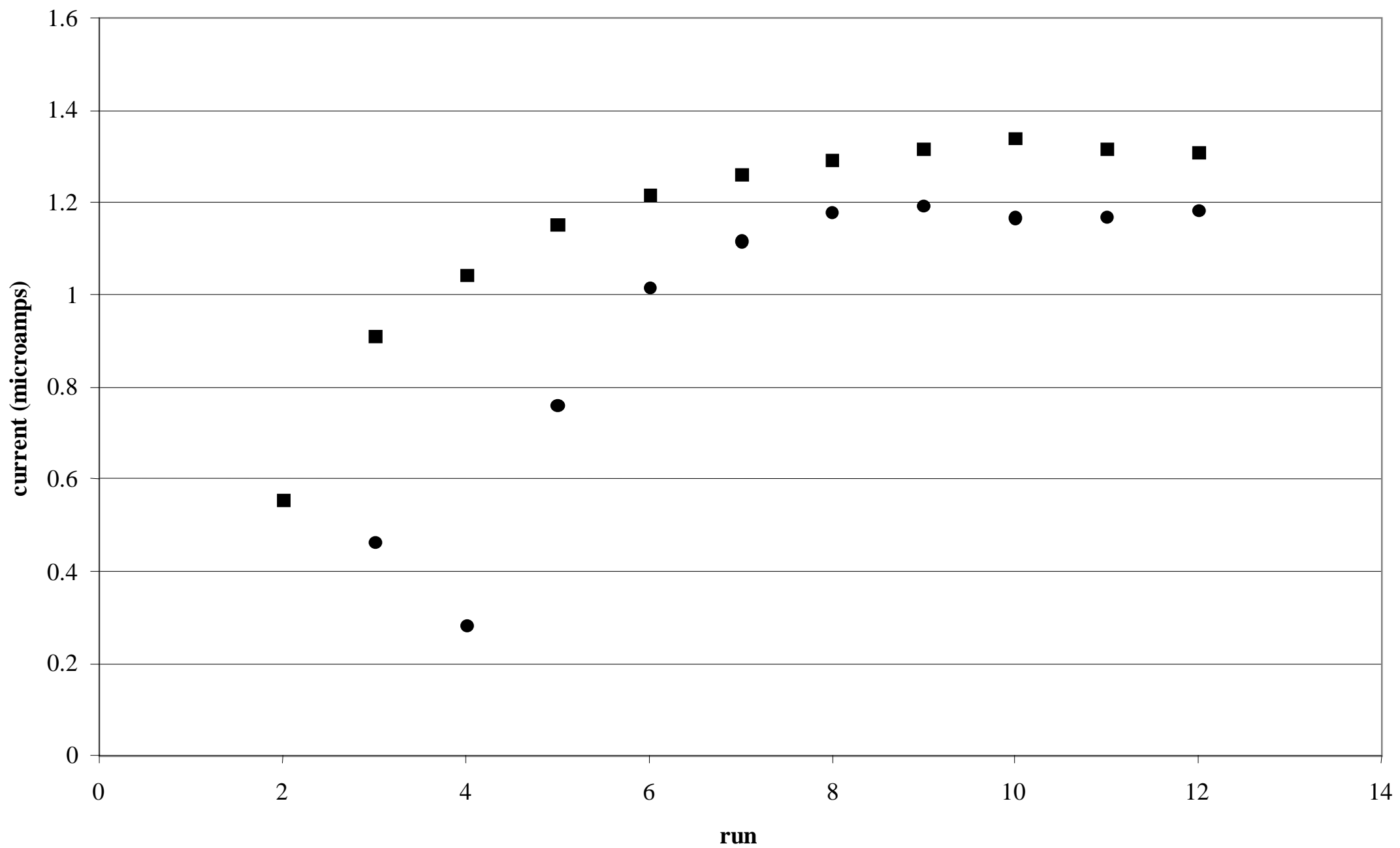

Figure 15. Comparison of MTF Plating Times: MTF plated with $\mathrm{N}_{2}$-stirring; $\left[\mathrm{Cd}^{2+}\right]=40 \mathrm{ppb}$; deposition time $=60$ seconds; analysis distance $=5 \mathrm{~mm}$. $\diamond$ MTF plated for 10 minutes, MTF plated for 5 minutes 


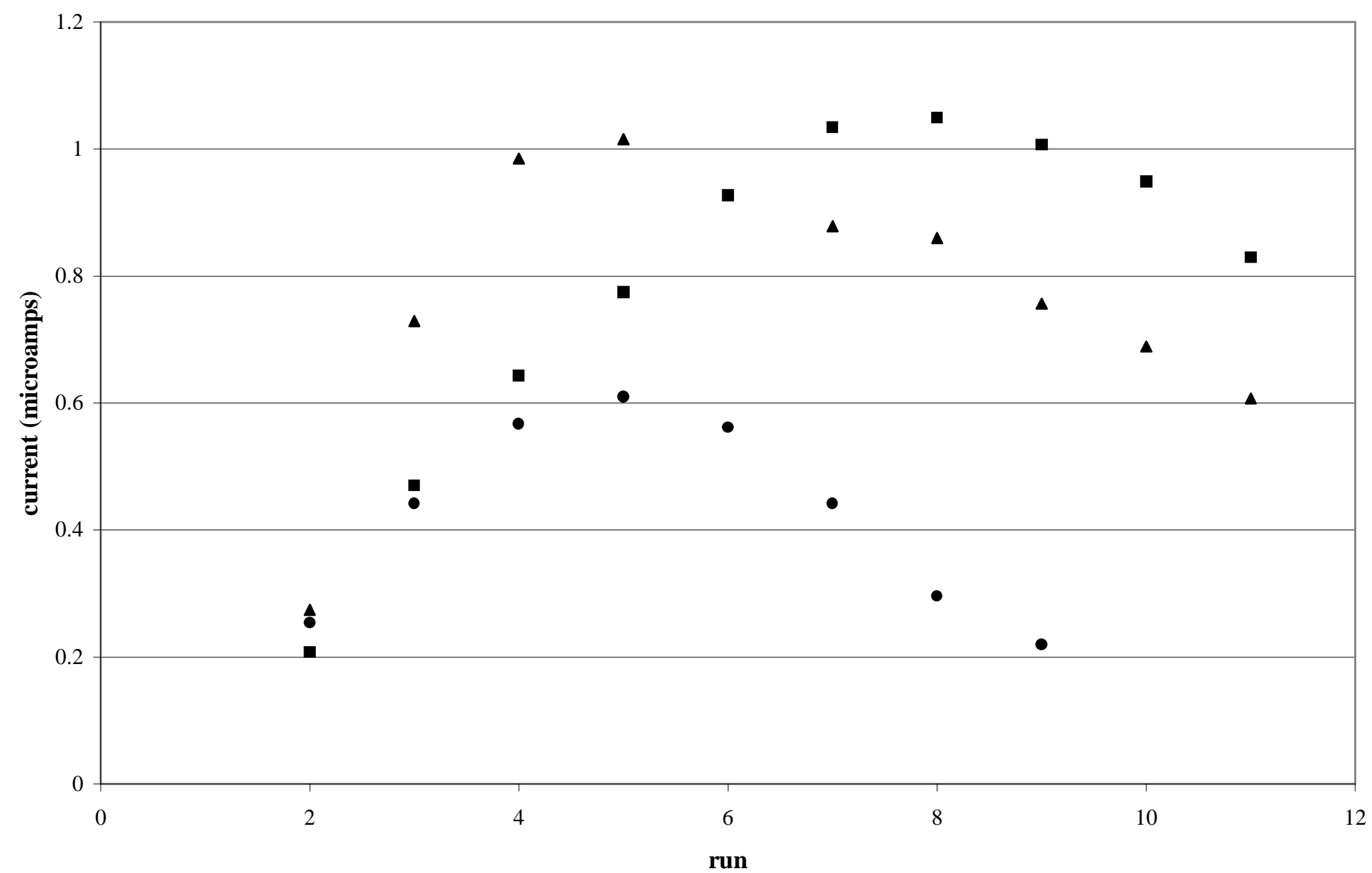

Figure 16. Comparison of MTF Plating Times: MTF plated with ultrasound at $15 \mathrm{~mm} ;\left[\mathrm{Cd}^{2+}\right]=40$ ppb; deposition time $=60$ seconds; analysis distance $=5 \mathrm{~mm}$. MTF plated for 10 minutes, $\Delta$ MTF plated for 5 minutes, $\square$ MTF plated for 3.5 minutes 
$\mathrm{KNO}_{3}$ solution which was placed between the electrode and the membrane was thoroughly de-gassed, but this proved not to be the problem. When working with glassy

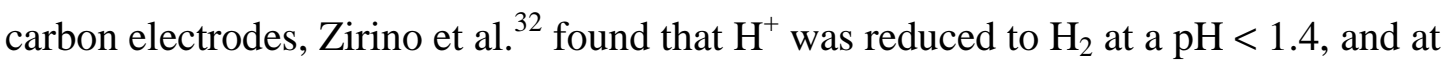
extremely negative potentials which interfered with the plating of the MTF. However, at $\mathrm{pH}>3.0$ with plating potentials between -300 and $-500 \mathrm{mV}$, no such reduction of $\mathrm{H}^{+}$ occurred. Therefore, the $\mathrm{pH}$ of the $\mathrm{Hg}^{2+}$ solution used to plate the MTF was adjusted to greater than 3.0. At this $\mathrm{pH}$, no bubble was observed after the plating of the MTF; however, during the deposition step in the cadmium analysis, small $\mathrm{H}_{2}$ bubbles still appeared on the mercury surface. This is probably due to the negative potentials needed in order to reduce $\mathrm{Cd}^{2+}$ during the deposition step. For the Pt-MCMTFE, the stripping current always decreased with time as shown in Figure 17. This was probably due to mercury loss from the electrode in the presence of ultrasound, and the growth of the $\mathrm{H}_{2}$ bubbles on the electrode surface.

\section{Conclusions}

The unexpected behavior of the Pt-MTFE was frustrating. In order for this electrode to be used in the presence of ultrasound for trace metal analysis, the technique would have to be made more sensitive and many initial scans prior to the plateau would need to be disregarded. Compton et al. 25 used a bare Pt-MTFE to detect lead in wine, and felt that the constant "roughening" of the surface in the presence of ultrasound did not allow adsorption of contaminants to occur. However, they reported a very large 


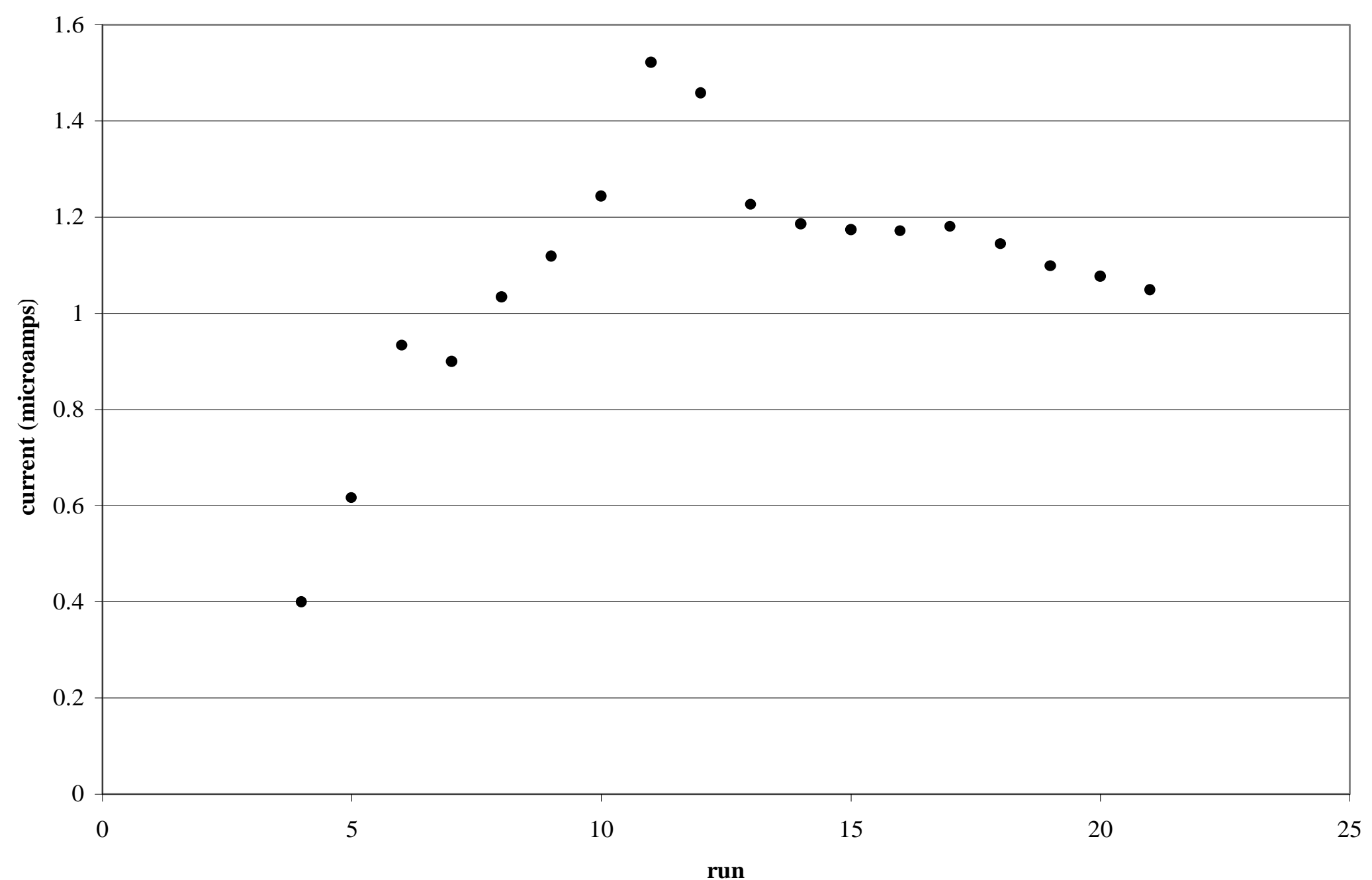

Figure 17. The Pt-MCMTFE: MTF plated while $\mathrm{N}_{2}$-stirring; $\left[\mathrm{Cd}^{2+}\right]=500 \mathrm{ppb}$; deposition time $=120$ seconds; analysis distance $=5$ $\mathrm{mm}$. 
RSD $( \pm 27 \%$ ) which was most likely due to the instability of the MTF in the presence of ultrasound. Therefore, even if the membrane is not needed in order to ensure that only metal can reach the electrode surface, some protection of the MTF from the effects of ultrasound is needed. The use of a membrane seems to be impossible in the case of the Pt-MTFE (due to $\mathrm{H}_{2}$ evolution). 


\section{CHAPTER III \\ THE GLASSY CARBON ELECTRODE}

\section{Introduction}

The coupling of ultrasound to the GC-MTFE has proven to be a difficult task. Brett et al 28 reported that the use of the GC-MTFE without a polymer coating was not suitable for sonovoltammetric studies. They also found that when the GC-MTFE was covered with a cellulose acetate membrane which was cast onto the electrode surface, it lifted off in the presence of ultrasound. The only successful use of a GC-MTFE was reported by Brett et al. in the same publication where the GCE was covered with a Nafion film. In order for the results to be reproducible, however, the MTF had to be plated in situ. The problem with using Nafion film in trace metal speciation studies is the negative charge associated with Nafion. The GC-MTFE was studied in the hope that, if it was covered with a cellulose acetate membrane which was not cast onto the electrode, the MTF would retain its stability.

\section{Experimental}

The GCE employed was $7.020 \mathrm{~mm}$ in diameter. There were two ultrasonic tips used in conjunction with the GCE. The microtip used has a diameter of $3.585 \mathrm{~mm}$ and is the same ultrasonic tip used with the platinum electrode. An ultrasonic macrotip with a diameter of $19.085 \mathrm{~mm}$ was also used occasionally. The experimental procedures described previously, and the parameters outlined in Table 3 were used unless otherwise stated. 
In all studies involving a "pitted" GCE, the electrode was pitted with the ultrasonic macrotip unless otherwise stated. The bare GCE was placed in $50 \mathrm{~mL}$ of water. The ultrasonic tip was then placed less than $5 \mathrm{~mm}$ from the electrode. The ultrasound was tuned to $15 \%$ power and the electrode was sonicated for 15 min.

\section{The GC-MTFE}

The GC-MTFE did not exhibit the peculiar behavior of the Pt-MTFE. After plating the MTF for ten minutes under $\mathrm{N}_{2}$-stirring, $\mathrm{Cd}^{2+}$ was added to the solution at a concentration of $40 \mathrm{ppb}$. When the stripping current was measured, the "plateau" effect seen with the Pt-MTFE in Figure 4 did not occur, and this current was constant after the

first run. The average current (neglecting the first run) obtained with $40 \mathrm{ppb} \mathrm{Cd}^{2+}$ and a deposition time of 60 seconds was 8.3091 (土. .0510) microamps.

The current associated with the stripping of cadmium for the uncovered GCMTFE in the presence of ultrasound was very erratic. Sometimes a peak could be seen, sometimes not. On the occasions when a peak could be seen, it was too small to quantify. Also, there was always a large shift associated with the stripping potential with a stirred deposition before and after ultrasound was applied. This shift was always in the negative direction, but when a stirred deposition step was immediately applied, the potential gradually shifted in the positive direction back to the original stripping potential. The peak current decreased in size after ultrasound was applied, and then similar to the potential, gradually increased with time. This suggested that the ultrasound was in some way modifying the MTF. Due to this behavior, all subsequent studies of the glassy carbon electrode were conducted with a membrane. 


\section{The GC-MCMTFE}

When the GCE is covered with a membrane, a curved plot of current vs. time is expected. This is due to the fact that the $\mathrm{Cd}^{2+}$ must equilibrate across the membrane. Once the $\mathrm{Cd}^{2+}$ concentration in the membrane is equal to the $\mathrm{Cd}^{2+}$ concentration of the bulk solution, the currents obtained should be reproducible. In Figure 18, this situation is represented by the "plateau" of the plot.

\section{Effect of Ultrasound on Current}

In the presence of ultrasound, a plot of time vs. current was expected to mirror Figure 18; however, as seen in Figure 19 this was not the case. The current reached a maximum, after which the current steadily decreased. Also, the current observed with ultrasound deposition was much smaller than the current measured where only stirring was employed. This was very puzzling, and opposite of the effect seen on the Pt-MTFE.

The first goal was to attempt eliminate the decrease in current observed when ultrasound was applied. According to Frenze 33 , a smooth, freshly polished GCE is not the best support material for a MTF. They found that the MTF could be mechanically deteriorated when a stream of liquid is directed toward the electrode surface. In our cell configuration known as the "face-on" geometry, there is a beam of liquid directed toward the surface of the electrode when using ultrasound known as the "acoustic stream." This geometry was used in all studies and has been shown previously in Figure 3. In order to prevent the MTF deterioration, Frenzel mechanically "roughened" the surface of GCE's by polishing with a diamond paste of $1-10 \mu \mathrm{m}$. Zhang and Coury found that severe 


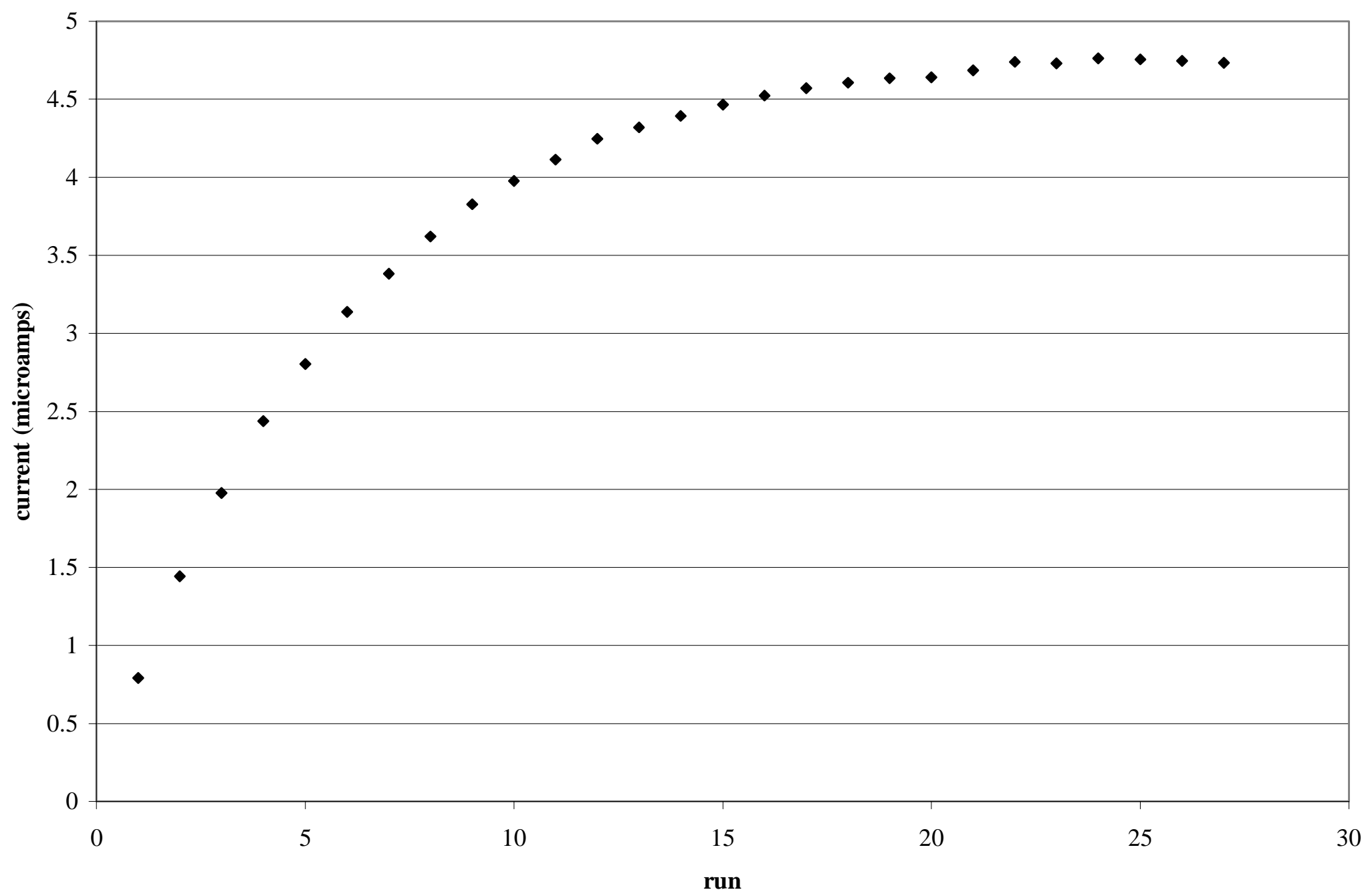

Figure 18. Behavior of the GC-MCMTFE: $\left[\mathrm{Cd}^{2+}\right]=40 \mathrm{ppb}$; deposition time $=90$ seconds; solution is stirred during analysis. 


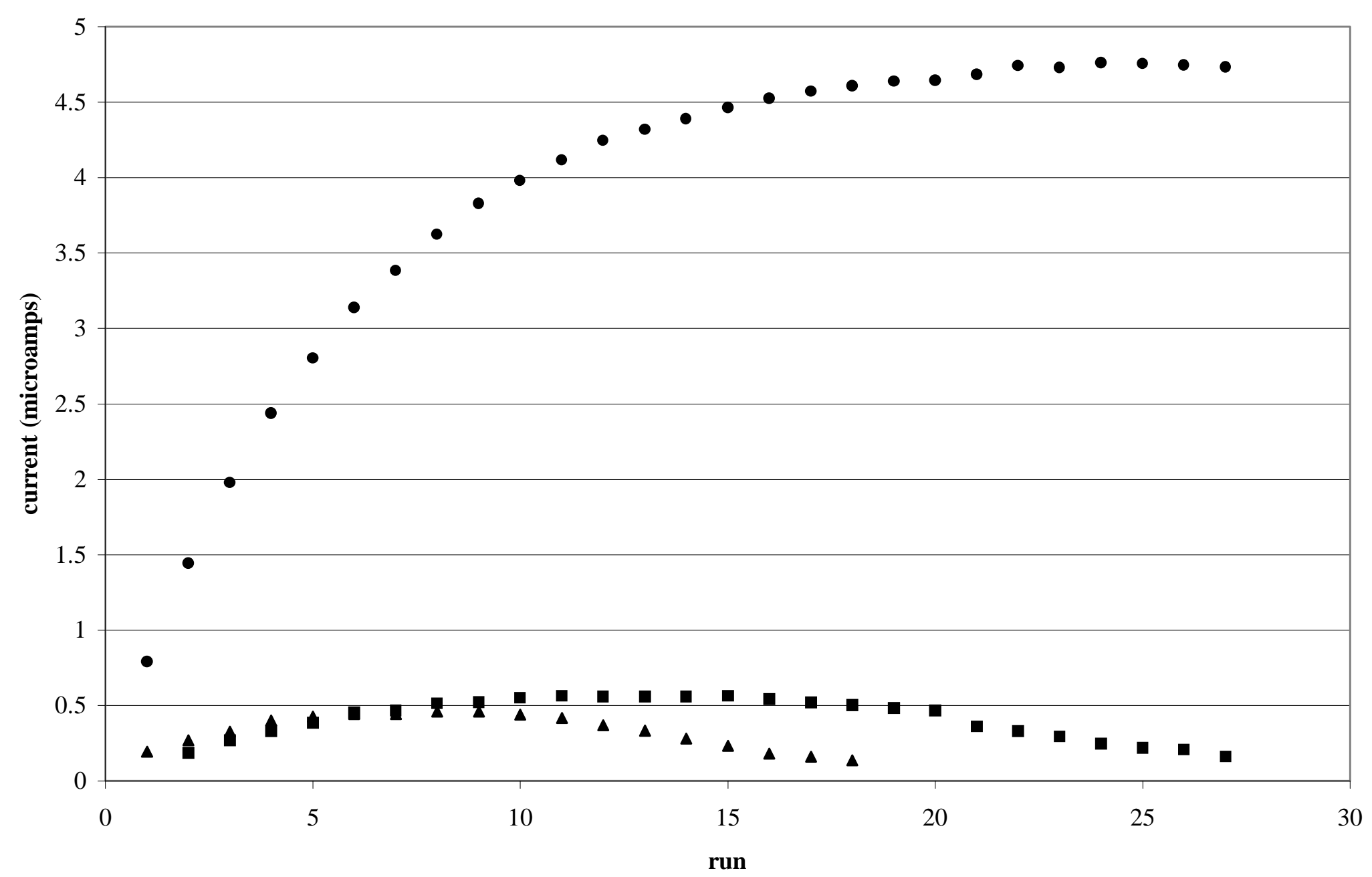

Figure 19. The Effect of Ultrasound on Current. $\left[\mathrm{Cd}^{2+}\right]=40 \mathrm{ppb}$; deposition time $=90$ seconds. stirring, $\boldsymbol{\Delta} 15 \mathrm{~mm}$, 口 $>15 \mathrm{~mm}$ 
pitting of the glassy carbon surface occured in the presence of ultrasound in aqueous solution. This technique was utilized in the following studies as a way to "roughen" the glassy carbon surface.

Although the current did not reach the current obtained using the polished GCE, pitting the GCE definitely increased the stability of the MTF as seen in Figure 20. Next, the GCE was pitted for 15 minutes with the ultrasonic macrotip located less than $5 \mathrm{~mm}$ from the bare electrode and the results are seen in Figure 21. The MTF is more stable when it is plated onto a "roughened" electrode, and the current is larger as the ultrasound is moved closer; however, the current is still much smaller than the current obtained during a stirred deposition.

The larger currents measured during a stirred deposition could be the result of a "pseudo" equilibrium established between the membrane and the bulk solution. During the deposition, the bulk solution was being stirred, but the solution between the membrane and the electrode was not. During the time between a stripping step and the next deposition, the $\mathrm{Cd}^{2+}$ may not have had enough time to diffuse out of the membrane. This would cause the concentration between the membrane and the electrode to be larger than the concentration in the bulk solution and perhaps explain the larger currents. Ultrasound should stir the solution between the membrane and the electrode as well as the bulk solution; so equilibrium should be established much quicker. This theory was tested by conducting an experiment which incorporated a 15 second quiet deposition. 


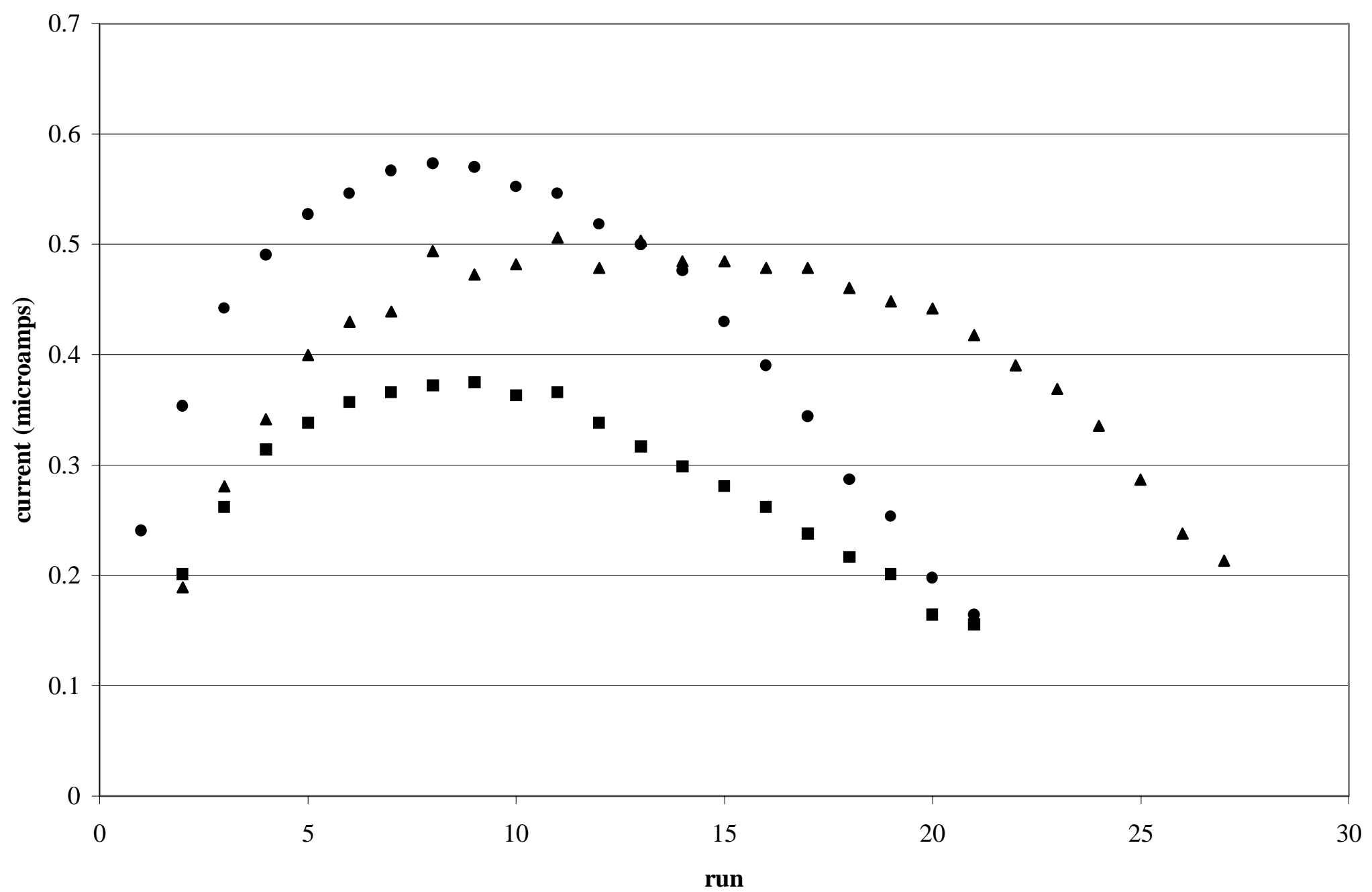

Figure 20. The Effect of Pitting on the GC-MCMTFE: pitting is attained with the ultrasonic microtip at $5 \mathrm{~mm}$; $\left[\mathrm{Cd}^{2+}\right]=40 \mathrm{ppb}$; deposition time $=90$ seconds; analysis distance $=15 \mathrm{~mm}$. polished, $\boldsymbol{\square}$ pitted 5 minutes, $\boldsymbol{\Delta}$ pitted 10 minutes 


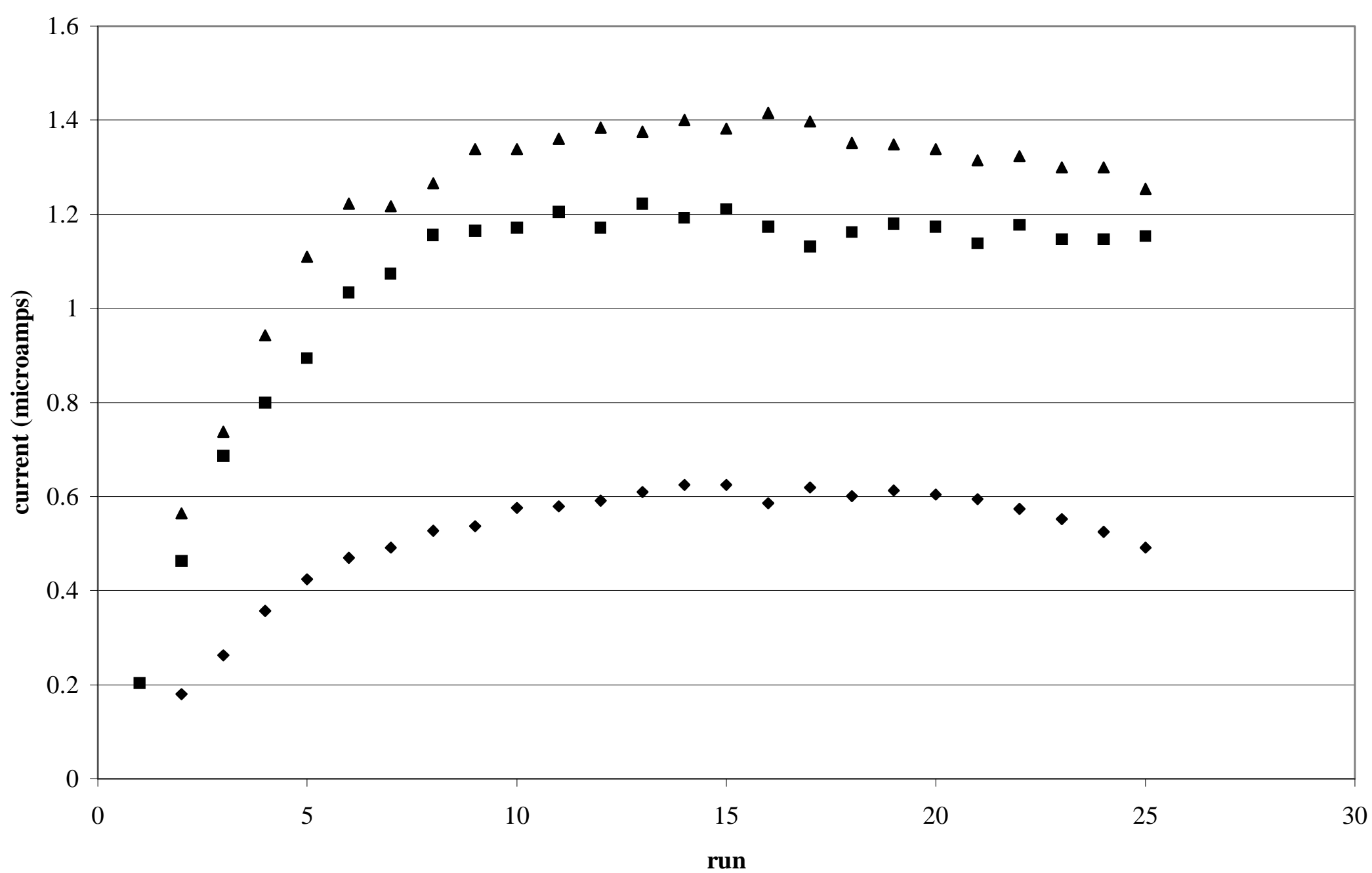

Figure 21. The Pitted GC-MCMTFE. GCE pitted with ultrasonic macrotip at $<5 \mathrm{~mm}$; $\left[\mathrm{Cd}^{2+}\right]=40$ ppb; deposition time $=90$ seconds. $\quad 15 \mathrm{~mm}, \boldsymbol{\square} 10 \mathrm{~mm}, \boldsymbol{\Delta} 5 \mathrm{~mm}$ 
Between each run, the solution was either stirred or ultrasound was applied for five minutes. This five-minute period between runs would, hopefully, give the $\mathrm{Cd}^{2+}$ time to diffuse out of the membrane. The results of this study are seen in Figure 22 and the currents were still very high. However, when the solution was stirred for a prolonged period of time, and then $\mathrm{Cd}^{2+}$ was deposited in the same manner, the stripping current was much smaller which supported the theory. When a run was taken using ultrasound for 5 minutes between the depositions, the current was always reduced by close to an order of magnitude. When stirring was applied immediately thereafter, the current increased to be at or very near its original value before the application of the ultrasound.

This led to the conclusion that while stirring is used during the deposition, the concentration may be slightly larger between the membrane and the electrode than in the bulk solution. The small currents obtained when ultrasound is used during or between depositions must be due to the ultrasound changing the MTF. Indeed, when the GCMCMTFE was removed after applying ultrasound, the center of the electrode appeared different from the edges, which was not true immediately after the MTF was plated. This inhomogeneity appeared to be due to more mercury present at the edge of the electrode, which agrees with the observation of Brett et a 28 


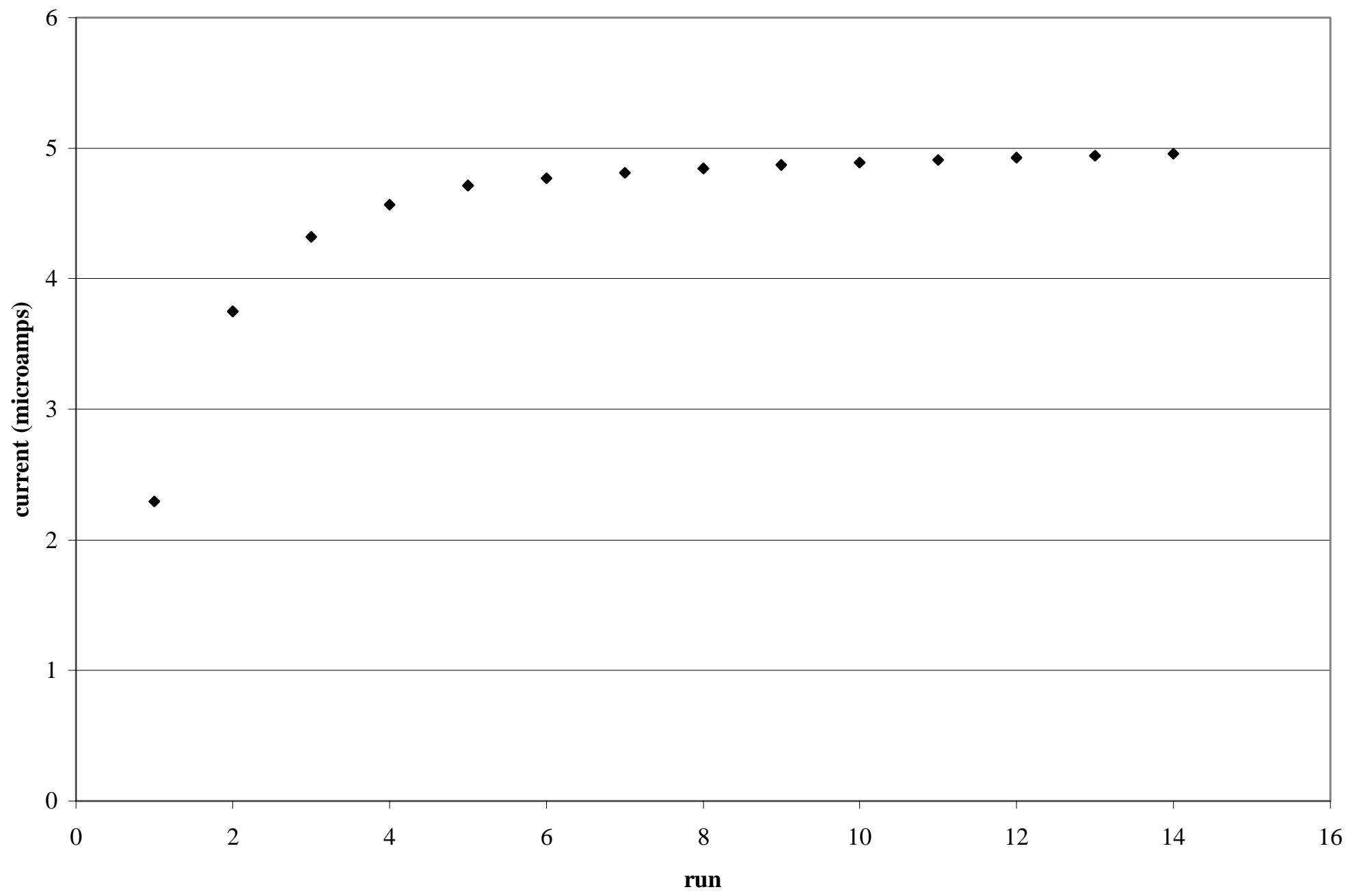

Figure 22. The GC-MCMTFE With a 15 Second Quiet Deposition: $\left[\mathrm{Cd}^{2+}\right]=160 \mathrm{ppb}$; solution is stirred for 5 minutes between runs. 


\section{Effect of Ultrasound on the Diffusion Coefficient of $\mathrm{Cd}^{2+}$}

The times needed to reach the plateau on the stripping current-time plot can be used to evaluate the diffusion coefficient, $\mathrm{D}_{\mathrm{m}}$, for $\mathrm{Cd}^{2+}$ in the membrane. The value of $D_{m}$ can be calculated using the following equation 34 35:

$$
\ln \left[\frac{C_{s o l}-C}{C_{s o l}-C_{m}}\right]=A+B\left(\frac{\pi^{2} D_{m} t}{l^{2}}\right)
$$

where $\mathrm{C}_{\mathrm{sol}}$ is the solution concentration, $\mathrm{C}_{\mathrm{m}}$ is the initial uniform concentration in the membrane, and $\mathrm{C}$ is the concentration at time $\mathrm{t}$ and $\mathrm{x}=\mathrm{o}$ (i.e., the electrode surface), and $\mathrm{A}$ and $\mathrm{B}$ are constants. This equation is based on numerical calculations of diffusion through a membrane of thickness 1 under the limiting condition $\left(0.2 \mathrm{C}_{\mathrm{sol}}+0.8 \mathrm{C}_{\mathrm{m}}\right) \leq \mathrm{C} \leq$ $\left(0.9 \mathrm{C}_{\text {sol }}+0.1 \mathrm{C}_{\mathrm{m}}\right)$. The slope of a plot of $\ln \left[\mathrm{C}_{\mathrm{sol}}-\mathrm{C} / \mathrm{C}_{\mathrm{sol}}-\mathrm{C}_{\mathrm{m}}\right]$ vs. time for the data of a stirred deposition shown in Figure 19 and the ultrasound experiment shown in Figure 21 was used to calculate $\mathrm{D}_{\mathrm{m}}$. The values for the $5 \mathrm{~mm}$ and $10 \mathrm{~mm}$ ultrasound data were calculated to be $3.87 \times 10^{-7}$ and $4.07 \times 10^{-7} \mathrm{~cm}^{2} \mathrm{~s}^{-1}$ respectively. The value of $\mathrm{D}_{\mathrm{m}}$ calculated for the stirred experiment was calculated to be $2.23 \times 10^{-7} \mathrm{~cm}^{2} \mathrm{~s}^{-1}$. Stewar ${ }^{36}$ calculated the value of $\mathrm{D}_{\mathrm{m}}$ for a similar membrane to be $1.87 \times 10^{-6} \mathrm{~cm}^{2} \mathrm{~s}^{-1}$ using a much larger $\mathrm{Cd}^{2+}$ concentration of $1.18 \times 10^{-2} \mathrm{M}$.

Bowers and Wilsor 37 reported that the diffusion coefficient for $\mathrm{Cd}^{2+}$ in a cellophane membrane was a function of the $\mathrm{Cd}^{2+}$ concentration and found that $\mathrm{D}_{\mathrm{m}}$ decreased as the $\mathrm{Cd}^{2+}$ concentration was lowered. They reported values of $\mathrm{D}_{\mathrm{m}}$ of $3.0 \times 10^{-7}$ $\mathrm{cm}^{2} \mathrm{~s}^{-1}$ at $0.0236 \mathrm{mM} \mathrm{Cd}^{2+}$ and $1.0 \times 10^{-6} \mathrm{~cm}^{2} \mathrm{~s}^{-1}$ at $6.23 \mathrm{mM} \mathrm{Cd}^{2+}$. They also suggested 
that adsorption of $\mathrm{Cd}^{2+}$ can occur within the membrane. When no $\mathrm{Cd}^{2+}$ is initially present in the membrane, a portion of that which enters during the establishment of steady state is adsorbed and never reaches the electrode. At the steady state, only the "free" $\mathrm{Cd}^{2+}$ is able to diffuse through the membrane.

It can be speculated that the plateau in Figure 21 is reached in about ten runs for the ultrasound experiments compared to over 20 runs for the stirred solution (Figure 19) as a result of ultrasound alteration of the membrane permeability. This might be the reason for the larger value of $\mathrm{D}_{\mathrm{m}}$ found with ultrasound.

\section{Effect of Ultrasound on Stripping Potential}

The effect of ultrasound on the GC-MTFE stripping current has been described above. The ultrasound also affected the stripping potential when the electrode was covered with a membrane. This effect was much less than the effect upon the bare electrode. The potential was generally shifted in the positive direction by around $30 \mathrm{mV}$. This is further evidence that the MTF is still being changed even when a membrane is covering the GCE. When stirring was immediately applied after the ultrasound, the potential shifted back to at or very near the original value.

\section{Conclusions}

The membrane does not seem to offer the MTF enough protection against degradation in the presence of ultrasound; however, pitting the GCE does offer some protection. The pitting process seems to preserve more of the mercury area, but not all of 
it, since the current in the presence of stirring seems is still much larger than the current in the presence of ultrasound. 


\section{CHAPTER IV}

\section{FUTURE WORK}

The MCMTFE has its primary use in the area of trace metal speciation, which requires that the MTF must be plated ex-situ and the integrity of the mercury film is of

great concern for any research in this area. It was hoped that the use of ultrasound would enable the analyte to reach equilibrium across the membrane faster than other stirring methods. This goal seems to be viable; however, the major problem for this technique to be effective is to find a way to protect the MTF.

The Spectra Por 6 membrane does not provide the MTF enough protection. "Pitting" the GCE before plating the MTF seems to offer this technique promise. Ultrasound alone does not seem to be the best way to "pit" the electrode, since some of the mercury is still displaced from the center of the electrode during analyte deposition. The future of the membrane-covered electrode could involve a mechanical alteration of the electrode surface to form a suitable substrate for the MTF. 


\section{REFERENCES}

${ }^{1}$ Copeland, T.R.; Skogerboe, R.K. Analytical Chemistry, 46, 1257A (1974).

${ }^{2}$ Vydra, F.; Stulik, K.; Julakova, E. Electrochemical Stripping Analysis. Halsted Press, NY, 1976.

${ }^{3}$ Aldstat, Joseph; Dewald, Howard D. Analytical Chemistry, 64, 3176 (1992).

${ }^{4}$ Christie, J.H.; Turner, John A.; Osteryoung, R.A. Analytical Chemistry, $\underline{49}, 1899$ (1977).

${ }^{5}$ Osteryoung, Janet G.; Osteryoung, R.A. Analytical Chemistry, 57, 101A (1985).

${ }^{6}$ Suslick, Kenneth. Science, 247, 1439 (1990).

${ }^{7}$ Suslick, Kenneth; Hammerton, D.A.; Cline, R.E. Jr. Journal of the American Chemical Society, 108, 5641 (1986).

${ }^{8}$ Gautherton, B.; Tainturier, G.; Degrand, C. Journal of the American Chemical Society, $\underline{107}, 5579$ (1985).

${ }^{9}$ Tainturier, G.; Gautheron, B.; Degrand, C. Organometallics, $\underline{5}, 942$ (1986).

${ }^{10}$ Degrand, C. Journal of Chemical Society, Chemical Communications, 1113 (1986).

${ }^{11}$ Bordeau, M.; Biran, C.; Leger-Lambert, M.P.; Dunogues, J. Journal of Chemical Society, Chemical Communications, 1476 (1991).

${ }^{12}$ Chyla, A.; Lorimer, J.P.; Mason, T.J.; Smith, G.; Walton, D.J. Journal of the Chemical Society, Chemical Communications, 603 (1989).

${ }^{13}$ Walthon, J.J.; Phull, S.S.; Bates, D.M.; Lorimer, J.P.; Mason, T.J. Electrochimica Acta, $\underline{38}, 307$ (1993).

${ }^{14}$ Klima, Jiri; Bernard, Claude; Degrand, Chantal. Journal of Electroanalytical Chemistry, 399, 147 (1995).

${ }^{15}$ Marken, Frank; Akkermans, Richard; Compton, Richard. Journal of Electroanalytical Chemistry, 415, 55 (1996).

${ }^{16}$ Marken, Frank; Compton, Richard. Journal of Physical Chemistry B, 100, 17395 (1996). 
${ }^{17}$ Brett, Ana Maria Oliveira; Matysik, Frank-Michael. Electrochimica Acta, $\underline{42}, 945$ (1997).

${ }^{18}$ Cooper, Evan L.; Coury, Louis A. Jr. Journal of the Electrochemical Society, 145 1994 (1998).

${ }^{19}$ Lauterborn, W.; Vogel, A. Annual Review of Fluid Mechanics, 16, 223 (1984).

${ }^{20}$ Zhang, Honghua; Coury, Louis A. Jr. Analytical Chemistry, 65, 1552 (1993).

${ }^{21}$ Compton, Richard; Eklund, John; Page, Stephen; Sanders, Giles; Booth, Jonathan. Journal of Physical Chemistry B, 98, 12410 (1994).

${ }^{22}$ Madigan, Nanette, Coury, Louis A. Jr. Analytical Chemistry, 69, 5 (1997).

${ }^{23}$ Birkin, P.R.; Silva-Martinez, S. Analytical Chemistry, 69, 2055 (1997).

${ }^{24}$ Leighton, T.G. The Acoustic Bubble, Academic Press, London, 1994.

${ }^{25}$ Compton, Richard; Eklund, John; Rebbitt; Akkermans, Richard; Waller. Electrochimica Acta, $\underline{42}, 2919$ (1997).

${ }^{26}$ Madigan, Nanette; Hagan, Carolynne R.S.; Coury, Louis A Jr. Journal of the Electrochemical Society, 141, L23 (1994).

${ }^{27}$ Akkermans, Richard; Ball, Jon C.; Rebbitt, Thomas; Marken, Frank; Compton, Richard. Electrochimica Acta, 43, 3443 (1998).

${ }^{28}$ Matysik, Frank-Michael; Matysik, Silke; Brett, Ana-Maria Oliveira; Brett, Christopher M.A. Analytical Chemistry, 69, 1651 (1997).

${ }^{29}$ Madigan, Nanette; Murphy, Tammy; Fortune, John; Hagan, Carolynne; Coury, Louis A. Jr. Analytical Chemistry, 67, 2781 (1995).

${ }^{30}$ Agra-Gutierrez, Cesar; Compton, Richard. Electroanalysis, 10, 204 (1998).

${ }^{31}$ Akkermans, Richard; Ball, Jon; Marken, Frank; Compton, Richard. Electroanalysis, $\underline{10}, 26$ (1998).

${ }^{32}$ Carra, R.; Snnchez-Misiego, A.; Zirino, A. Analytical Chemistry, 67, 4484 (1995).

${ }^{33}$ Frenzel, Wolfgang. Analytica Chimica Acta, 273, 123 (1993). 
${ }^{34}$ Belmont-Hebert, C.; Tercier, M.L.; Buffle, J.; Fiaccabrino, G.C.; de Rooij, N.F.; Koudelka-Hep, M. Analytical Chemistry, 70, 2949 (1998).

${ }^{35}$ Jost, W. Diffusion in Solids, Liquids, and Gases, $3^{\text {rd }}$ ed., Academic Press, NY, 1960.

${ }^{36}$ Stewart, E. M.S. Thesis, West Virginia University, Morgantown, WV, 1983.

${ }^{37}$ Bowers, R.C.; Wilson, A.M. Journal of the American Chemical Society, 무, 2968 (1958). 